\title{
La gestión efectiva de fiscalización y los programas de control intensivo de la DIAN como elementos del control tributario contra la evasión de los impuestos nacionales para los años 2011 a 2016
}

\section{Effective Inspection Management and Intensive Control Programs in DIAN as elements of Tax Control against the Evasion of National Taxes for the years 2011 to 2016}

\author{
DANIEL ENRIQUE GONZÁLEZ RODRÍGUEZ ${ }^{1}$
}

\section{Resumen}

A pesar de que la DIAN cuenta con instrumentos de planeación, gestión, medición y evaluación del control tributario y ha definido objetivos para modernizar la fiscalización y se han asignado recursos de inversión con los que se ha pretendido mejorar los resultados del proceso, en la práctica, debido al mantenimiento de las tendencias de las tasas de evasión en los mismos márgenes en los años 2010 a 2016, se puede considerar que los avances han sido insuficientes. Así mismo, a pesar de los sobrecumplimientos en sus metas de gestión efectiva de fiscalización para el mismo periodo 2010-2016 (159\%), ello no ha contribuido a ejercer presión fiscal sobre las altas brechas de evasión impositiva en Colombia, resultando insuficiente que mediante reformas tributarias se pretenda contrarrestar la evasión fiscal sin constituir un aparato institucional a fin de hacer realizable la necesaria modernización y fortalecimiento del control tributario.

${ }^{1}$ Abogado de la Universidad Nacional de Colombia y Contador Público de la Universidad Central, Máster en Derecho con Énfasis en Tributación de la Universidad Externado de Colombia, especialista en Derecho Privado Económico y en Revisoría Fiscal y Contraloría, con experiencia de más de 12 años en administraciones tributarias en áreas de fiscalización, jurídica, cobranzas, auditoría y control interno.Correo-e: Dgon95@yahoo.com DOI: https://doi.org/10.18601/16926722.n13.07 
Palabras clave: Fiscalización tributaria, impuestos nacionales, evasión fiscal, percepción de riesgo subjetivo, DIAN, control tributario, gestión efectiva de fiscalización.

\section{Abstract}

Although the DIAN has instruments for planning, management, measurement and evaluation of tax control, it has defined objectives to modernize the audit and investment resources have been allocated with which it has been tried to improve the results of the process, in practice, due to the maintenance of evasion rates trends in the same margins from the years 2010 to 2016 , it can be considered that the progress has been insufficient. In spite of over-performance in its effective control management goals for the same period 2010-2016 (159\%), this has not contributed to exert fiscal pressure on the high tax evasion gaps in Colombia. tax reforms are intended to counter fiscal evasion without constituting an institutional apparatus in order to make feasible the necessary modernization and strengthening of tax control.

Keywords: Tax inspection, National taxes, Tax evasion, Perception of subjective risk, DIAN, Tax control, Effective control management.

\section{Introducción}

De acuerdo con análisis del Banco Mundial (2015), Colombia se encuentra entre los países con mayores problemas en términos de desigualdad, redistribución del ingreso y pobreza. Según los indicadores y análisis estadísticos, si bien el coeficiente GINI (Comisión Económica para América Latina y el Caribe (Cepal, 2015) estimado del país ha presentado un ligero incremento desde el año 2011 a 2016 pasando de 0,548 a 0,517, las cifras comparativas del Banco Mundial (2016) indican que Colombia se encuentra en el puesto 11 a nivel mundial entre 168 evaluados, dentro de los países con mayores niveles de desigualdad en lo relativo a la distribución del ingreso.

Dicha circunstancia hace imperiosa la necesidad de que el Estado constituya un sistema tributario fuerte. Para ello, además de la consolidación de un conjunto normativo tributario simplificado y eficaz fundado en los principios constitucionales de equidad, eficiencia y progresividad, se necesita la conformación de un ente tributario protagónico que pueda materializar efectiva y realmente estos principios y que responda al desarrollo del país y la sostenibilidad de las finanzas públicas.

En este contexto, se torna de vital importancia la necesidad de reforzar la inteligencia del sistema institucional y los procesos de fiscalización con metodologías innovadoras de identificación de prácticas y focos de elusión y evasión, asignando los recursos humanos, físicos, tecnológicos y de información suficientes e idóneos, con una medición objetiva y cierta de los resultados del proceso y el establecimiento de controles que permitan retroalimentar, redirigir y reenfocar oportunamente la función fiscalizadora con una fijación de metas debidamente direccionadas que propendan a atacar de manera contundente la evasión tributaria, que según la DIAN, en renta de personas jurídicas se sitúa en $39 \%$ para 2014 y en el impuesto a las ventas en un $23 \%$ (DIAN, 2016). 
El presente artículo tiene como propósito principal realizar un examen a la gestión y a los resultados de la fiscalización y el control tributario que adelanta la DIAN conforme a sus competencias legales, centrando el estudio en el elemento de medición principal que se ha creado y que se denomina "la gestión efectiva de fiscalización", así como otros instrumentos gerenciales, operativos, de medición y evaluación.

En este sentido, en un primer lugar, se analizará el escenario del ejercicio del control tributario en Colombia, donde se examinará la situación en términos de ingresos tributarios en el que se encuentra el país, pasando a dar una mirada a los resultados de los ingresos fiscales del orden nacional, para después presentar los resultados de las mediciones de la evasión tributaria que realiza la DIAN.

En una segunda parte, se desarrollará una evaluación de la gestión de fiscalización en materia tributaria desarrollada por la DIAN. Así se da cuenta del impacto que tiene la gestión de control tributario frente a las mismas proyecciones de evasión tributaria estimadas; se examinará la focalización y el énfasis dado a la gestión de control tributario y en qué se concentran los recursos y los esfuerzos, y estudia la gestión de control tributario (programas de fiscalización) desarrollada en los seis (6) últimos años en cuanto a sus enfoques y el alcance frente al universo de declaraciones y contribuyentes obligados.

Lo anterior, para proponer, por último, unas conclusiones de la gestión y la evalua- ción de la fiscalización tributaria de los impuestos del orden nacional y el desempeño en las actividades de control tributario.

\section{El escenario de la evasión de los impuestos nacionales y los principales elementos de la fiscalización tributaria del orden nacional para su reducción}

\section{A. Representatividad del recaudo de tributos del orden nacional por clase de impuesto para los años 2011-2016}

La DIAN, entre los años 2011-2016, ha presentado los siguientes resultados en términos de ingresos por administración de impuestos internos y externos (véase cuadro 1).

Como se puede observar, los impuestos que representan el mayor volumen de recaudo corresponden al impuesto de renta y complementarios y el impuesto al valor agregado (IVA). Para los años 2011-2016, los valores de ingresos por estos dos impuestos respecto al total recaudado por la DIAN ${ }^{2}$ representaba: para el año 2011, 69,22\%; para 2012, 72,84\%; para 2013, 67,93\%; para $2014,59,27 \%$; para 2015, el 57,38\%; y para 2016, el 58,52\%.

Si en esta comparación se incluye en el cálculo de la participación de estos dos impuestos al CREE para los años 2013-2016, se tendría: para 2013, un 74,59\%; para 2014, un $80,67 \%$; para 2015 , un $85,52 \%$, y para 2016 , un $89,26 \%$, resultados que permiten evidenciar una importante tendencia al in-

\footnotetext{
${ }^{2}$ Tomando como base la suma del total de la actividad interna + actividad externa de las estadísticas de ingresos tributarios administrados por la DIAN - Años 2011-2016.
} 


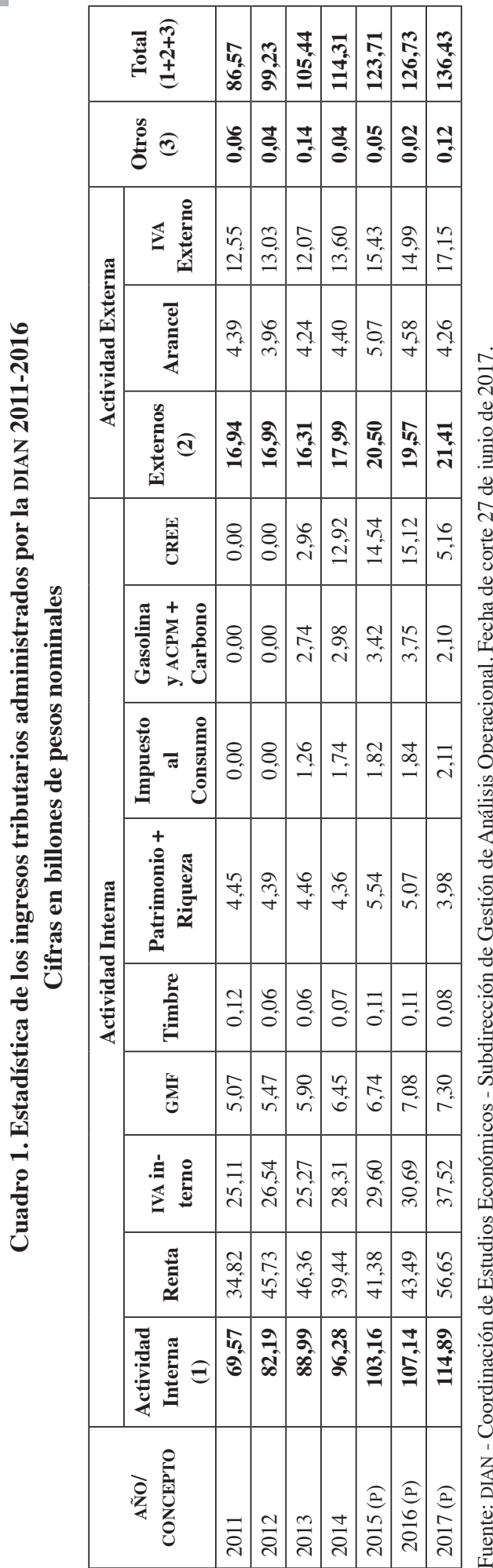

cremento en la participación de los recursos de estos impuestos dentro de la totalidad de los ingresos tributarios administrados por la DIAN, hecho que justifica intensificar y concentrar el control tributario en estos conceptos de tributos, enfocando su capacidad operativa y su fuerza fiscalizadora en estos dos, lo que propendería a la eficiencia en su gestión de fiscalización, motivo por el cual, el presente estudio se centra más adelante en la evasión fiscal frente a estos dos impuestos.

En este punto, es necesario detenernos y realizar una aproximación conceptual a ciertas definiciones como la evasión tributaria, para poder presentar los resultados de las mediciones y proyecciones oficiales de este fenómeno en Colombia, advirtiendo preliminarmente que se encuentran limitaciones en términos de información disponible, ya que la autoridad tributaria únicamente ha realizado estudios respecto a la evasión del impuesto sobre la renta de personas jurídicas y del impuesto a las ventas.

\section{B. La evasión tributaria}

La evasión tributaria podría ser entendida como la disminución o no pago de un tributo por quienes están obligados a abonarlo, obteniendo así beneficios mediante comportamientos fraudulentos, o como el incumplimiento total o parcial de las obligaciones tributarias definidas en la ley (Camargo, 2005).

Así las cosas, encontramos que un factor determinante en la evasión tributaria se origina en la decisión voluntaria de los sujetos pasivos del tributo de infringir la 
norma. Por ello, adquiere importancia un concepto que la DIAN ha nombrado en sus instrumentos de planeación, de cara al cumplimiento voluntario de las obligaciones, el cual se enmarca en la percepción del riesgo subjetivo por parte de los obligados contribuyentes. En efecto, dicho concepto se podría entender como "la mayor o menor probabilidad de ser revisado e incidido por la acción del organismo fiscalizador estatal" (Auditoría y planeación tributaria, 2015), resultando determinante desde este propósito el crear dentro del discernimiento de los contribuyentes que el incumplimiento particular de las obligaciones tributarias va a activar la institucionalidad tributaria para encausar dicha conducta tributaria anómala, por lo que el hecho de crear en el imaginario colectivo la existencia de un ente fiscal eficaz que emprenda de cara al incumplimiento del obligado las acciones institucionales consecuentes, se encuentra correlacionado con una función fiscalizadora y control tributario altamente competente, con miras a enderezar actos tributarios anómalos y conseguir resultados de recaudo conforme a las realidades económicas y los términos impositivos señalados en las normas fiscales, disminuyendo las brechas de evasión existentes.

Un aspecto fundamental que se halla tanto en los informes del Banco Mundial (2015), de la OCDE (2015), como en el final de la Comisión de Expertos (2015) que afecta el cumplimiento voluntario de las obligaciones tributarias e incrementa la evasión tributaria, se encuentra relacionado con "la reducida eficiencia con la cual opera la administración para identificar quienes evaden al fisco y hacerlos cumplir" (Comisión de Expertos, 2015), por lo que es necesario el fortalecimiento de las administraciones tributarias, motivo por el cual, resulta oportuna la realización del presente trabajo, donde se evaluará la gestión de la fiscalización tributaria, para lo cual, seguidamente, se presentan las estimaciones oficiales de evasión tributaria.

\section{Cálculos de evasión tributaria}

En este aparte, se presentan las cifras oficiales y académicas de evasión tributaria en el impuesto sobre la renta de personas jurídicas y en el impuesto al valor agregado (IVA), haciendo la salvedad de que los estudios disponibles datan de informaciones de años anteriores. No obstante, se encuentra relevante presentarlos con el fin de realizar un acercamiento al panorama de la evasión fiscal en Colombia.

\section{i. Evasión en el impuesto sobre la renta de personas jurídicas}

Dentro de un análisis efectuado por la DIAN (2016), en el cual, para la determinación de la tasa de evasión, se toman valores de impuesto a cargo liquidado e impuesto a cargo potencial (y no de renta líquida), se obtuvieron resultados que reflejaban tasas de evasión (véase cuadro 2).

De las cifras del cuadro anterior, se observa que se establecen unos nuevos valores estimados de tasas de evasión en renta jurídicas que oscilan entre $34 \%$ y $45,2 \%$ para los años 2007-2013, presentando un panorama similar al expuesto en estudios académicos en el caso del impuesto de renta, en los que se había estimado que la tasa de evasión promedio de las personas jurídicas para el periodo 2007-2012 se ubica en un nivel de $39 \%$ (Cruz, 2015), lo que, siendo más desalentador, deriva en la necesidad de que el 
Cuadro 2. Colombia. Impuesto de renta de personas jurídicas. Costo fiscal de la tasa de evasión

(Miles de millones de pesos corrientes)

\begin{tabular}{|l|c|c|c|c|c|c|c|}
\hline \multicolumn{1}{|c|}{ Concepto - Año } & $\mathbf{2 0 0 7}$ & $\mathbf{2 0 0 8}$ & $\mathbf{2 0 0 9}$ & $\mathbf{2 0 1 0}$ & $\mathbf{2 0 1 1}$ & $\mathbf{2 0 1 2}$ & $\mathbf{2 0 1 3}$ \\
\hline $\begin{array}{l}\text { Impuesto a cargo } \\
\text { declarado }\end{array}$ & 16.051 & 19.343 & 16.428 & 18.927 & 28.970 & 28.972 & 23.832 \\
\hline Impuesto potencial & 26.515 & 30.692 & 29.592 & 33.395 & 43.896 & 44.106 & 37.014 \\
\hline $\begin{array}{l}\text { Monto total de la } \\
\text { evasión }\end{array}$ & 10.464 & 11.349 & 13.164 & 14.468 & 14.926 & 15.134 & 13.182 \\
\hline Evasión / PIB\% & $2,4 \%$ & $2,4 \%$ & $2,7 \%$ & $2,7 \%$ & $2,4 \%$ & $2,3 \%$ & $1,9 \%$ \\
\hline $\begin{array}{l}\text { Valor punto de } \\
\text { evasión }\end{array}$ & 265 & 307 & 300 & 334 & 439 & 441 & 370 \\
\hline Tasa de evasión & $\mathbf{3 9 , 5 \%}$ & $\mathbf{3 7 , 0 \%}$ & $\mathbf{4 5 , 2 \%}$ & $\mathbf{4 3 , 3 \%}$ & $\mathbf{3 4 , 0 \%}$ & $\mathbf{3 4 , 3 \%}$ & $\mathbf{3 5 , 6 \%}$ \\
\hline
\end{tabular}

Fuente: Informe Plan de Choque contra la Evasión 2016 - DIAN.

ente fiscal deba ampliar el alcance de control tributario, máxime si han adoptado reformas como la prevista en la Ley 1607 de 2012, que amplían el universo de contribuyentes obligados frente a este impuesto.

Por otra parte, a pesar de no contar con cifras actualizadas de medición de la evasión en renta como ya se ha indicado, se considera que la evasión en este impuesto, en la actualidad, puede presentar una tendencia similar o mayor a la observada en el último año analizado que correspondió al año 2013.

Lo anterior, teniendo en cuenta que los valores de recaudo en este impuesto, desde el último año en que se calculó la tasa de evasión (2013) hasta el año 2016, sumando los valores de recaudo del derogado impuesto sobre la renta para la equidad (CREE) $)^{3}$, no presentan el mismo dinamismo de aumento de cara al crecimiento del Producto Interno Bruto (PIB) para los mismos años analizados, tal como se nota en el cuadro 3 (DIAN 2017).

Por consiguiente, si se observan los incrementos de recaudo en el impuesto de renta y el hoy inexistente impuesto de renta para la equidad CREE para los años 2014-2016, que se ubican en $4,14 \%, 3,03 \%$ y $-1,86 \%$ respectivamente frente al año anterior al analizado, no se encuentra que estos comportamientos sean consistentes con el incremento en la producción nacional (PIB), donde los incrementos del PIB generan mayores ingresos para la economía en general y para los diversos agentes económicos, pero no produjeron un mayor recaudo de impuesto de renta y CREE, por lo que las estimaciones oficiales de evasión que para renta personas

\footnotetext{
${ }^{3}$ Se suman los valores de recaudo de estos dos impuestos, teniendo en cuenta la diferencia de tarifa para los periodos analizados, toda vez que el recaudo de renta del año 2013 correspondió a las declaraciones presentadas por la vigencia fiscal 2012, año gravable en el cual no había entrado en vigencia la Ley 1607 del 26 de diciembre de 2012 y que presentó diferencia en la tarifa del impuesto de renta frente a la vigencia fiscal 2012 y anteriores, por lo que, para el cálculo, se suman estos dos impuestos: renta y renta para la equidad CREE.
} 
jurídicas del año 2013 la ubicaban en 35,6\% permitirían inferir que para los años 2014 a 2016 reflejarían unas tasas de evasión mayores, lo que hace imperiosa la necesidad de fortalecer las administraciones tributarias y la eficacia del control y fiscalización tributaria para que el incremento en la producción nacional derive un incremento en el recaudo tributario del impuesto sobre la renta.

\section{ii. Evasión en el impuesto a las ventas (IVA)}

Para el cálculo de la tasa de evasión del IVA, la DIAN toma el valor estimado del recaudo potencial menos el recaudo bruto obtenido, y el resultado lo divide entre el recaudo potencial, encontrando que para los años 2009-2013 se presentan evasiones estimadas en este impuesto que van de los 9,8 a los 11,85 billones de pesos (véase cuadro 4).
De acuerdo con las mediciones oficiales, se observa una tendencia a la disminución en la evasión de este impuesto, tendencia que la Administración espera consolidar, ya que, como se verá más adelante, dentro de los objetivos trazados por la DIAN en su planeación, se espera reducir la evasión en el impuesto al valor agregado - IVA, del $23 \%$ al $21 \%$ en 2015, y así de manera progresiva anualmente, hasta lograr una reducción en el 2018 al $11 \%$, para lo cual, se espera implementar diversos instrumentos de control, siendo el más importante dentro del plan de choque contra la evasión el proyecto formulado desde 2015, relativo a la "Implementación, impulso y masificación de la factura electrónica", con el que se pretende ejercer una presión importante para lograr reducir la brecha de evasión del IVA.

Cuadro 3. Comparativo del comportamiento del recaudo renta + renta CREE años 2014, 2015 y 2016, frente al incremento del PIB

\begin{tabular}{|l|c|c|c|c|}
\hline \multirow{2}{*}{ Año } & $\begin{array}{c}\text { Valor recaudo renta } \\
\text { +renta CREE (en } \\
\text { billones \$\$ a valor } \\
\text { presente) }\end{array}$ & $\begin{array}{c}\text { Incremento recaudo } \\
\text { frente a año anterior) } \\
\text { (en billones \$\$) }\end{array}$ & $\begin{array}{c}\text { Incremento recaudo } \\
\text { frente a año } \\
\text { anterior) (en \%) }\end{array}$ & PIB (\%) \\
\cline { 1 - 4 } 2013 (Línea base) & 58,844 & 2,437 & $\mathbf{4 , 1 4 \%}$ & $\mathbf{4 , 6 \%}$ \\
\hline 2014 & 61,281 & 1,859 & $\mathbf{3 , 0 3 \%}$ & $\mathbf{3 , 1} \%$ \\
\hline 2015 & 63,140 & $-1,174$ & $-1,86 \%$ & $2,0 \%$ \\
\hline 2016 & 61,966 & &
\end{tabular}

Fuente: Estadísticas ingresos tributarios de la Subdirección de Gestión de Análisis Operacional DIAN y PIB e IPC DANE.

\section{Cuadro 4. Estimación de la evasión en el IVA total 2009-2013pr}

(Miles de millones de pesos)

\begin{tabular}{|l|c|c|c|c|c|c|}
\hline \multicolumn{1}{|c|}{ Año } & $\begin{array}{c}\text { Recaudo } \\
\text { potencial }\end{array}$ & $\begin{array}{c}\text { Recaudo } \\
\text { bruto }\end{array}$ & Evasión & Evasión/PIB & Tasa evasión & $\begin{array}{c}\text { Punto } \\
\text { evasión }\end{array}$ \\
\hline 2009 & 37,963 & 28,049 & 3,914 & $1,96 \%$ & $26,1 \%$ & 380 \\
\hline 2010 & 41,787 & 31,362 & 10,425 & $1,92 \%$ & $24,9 \%$ & 418 \\
\hline 2011 & 48,67 & 37,659 & 10,011 & $1,77 \%$ & $22,6 \%$ & 487 \\
\hline $2012 \mathrm{p}$ & 51,429 & 37,579 & 11,85 & $1,78 \%$ & $23,0 \%$ & 514 \\
\hline $2013 \mathrm{pr}$ & 47,114 & 37,293 & 9,82 & $1,39 \%$ & $20,8 \%$ & 471 \\
\hline
\end{tabular}

Fuente: Informe Plan de Choque contra la Evasión 2016 - DIAN. 
No obstante, para el año 2014, la medición de la tasa de evasión del IVA llegó al $23 \%$ (DIAN, 2016), presentando un incremento en este año respecto a los anteriores, rompiendo la tendencia a la disminución que se esperaba conforme los estudios de planeación.

Como conclusión de lo anterior, llama la atención el escenario de evasión de los dos impuestos que representan los mayores volúmenes de recaudo nacional, teniendo en cuenta que de estimaciones oficiales, en el impuesto de renta de personas jurídicas, para el año 2013, conforme a los últimos cálculos realizados (DIAN, 2016), esta evasión presenta un porcentaje del 35,6\% y se estima en $\$ 13,18$ billones de pesos, donde la situación actual es más desalentadora (año 2016), toda vez que los valores del recaudo del impuesto de renta como del impuesto de renta para la equidad CREE para los años 2014-2016 han presentado incrementos que no se compadecen con los aumentos del PIB para las mismas vigencias, lo que permitiría inferir que para los años 2014-2016 se estiman unas tasas de evasión similares o mayores a las vistas para el año 2013.

Por otra parte, en cuanto a la evasión del IVA, se observan tasas del $23 \%$ para 2012, $20,8 \%$ para 2013, y conforme a últimos estudios realizados (DIAN, 2016), de $23 \%$ en 2014, evidenciándose una tendencia al incremento en el año 2014 frente al comportamiento de los años anteriores.

Además, como ya se advirtió sobre las limitaciones de estos cálculos oficiales pues comprenden solamente el IVA y parcialmente el impuesto de renta de personas jurídicas, sin incluir estudios respecto a los demás impuestos, las mediciones de evasión realizadas en otros estudios (OCDE, 2015), y en cálculos más recientes del Fondo Monetario Internacional (FMI) y algunos analistas, sitúan las cifras de evasión de IVA en el doble del nivel calculado oficialmente (Steiner y Medellín, 2014), donde, como ya se analizó, el panorama actual en cuanto al comportamiento de la evasión puede ser mucho más gravoso que los escenarios presentados en las vigencias anteriores, teniendo en cuenta la relación inversa entre recaudo de impuestos frente al crecimiento de la economía.

Una vez presentado (con todas las limitaciones del caso ya expuestas) el escenario de la evasión en Colombia en cuanto al IVA y el impuesto de renta, a continuación se presentarán brevemente, y desde una perspectiva crítica, las principales características de la gestión del control tributario ejercido por parte de la DIAN, las herramientas de gestión, medición y evaluación de la fiscalización tributaria que se han implementado para reducir dicha evasión, y los elementos gerenciales, de planeación y control creados para desarrollar la gestión y las actividades de control tributario.

\section{Análisis crítico de los aspectos relevantes del proceso de fiscalización y liquidación de la DIAN de los años 2011-2016}

\section{Aspectos relevantes del proceso de} fiscalización y liquidación de la DIAN

Para desarrollar su gestión, la DIAN (2017) ha implementado un modelo de gestión por 
procesos, donde se han diseñado ocho (8) procesos misionales ${ }^{4}$, cuatro (4) de apoyo ${ }^{5}$, dos de control ${ }^{6}$ y uno estratégico que se denomina Inteligencia Corporativa.

Haciendo referencia a la gestión propiamente dicha de fiscalización tributaria, esta se recoge, por una parte, dentro del proceso de Gestión Masiva respecto a las actividades de Control Extensivo, que conforme el Manual de Lineamientos de Fiscalización (DIAN, 2013) tienen que ver con acciones orientadas a prevenir el incumplimiento de obligaciones fiscales, cubriendo de manera masiva a diversos clientes de sectores económicos o geográficos y pueden servir de insumo para las acciones de control intensivo, conforme a la expresión normativa en la legislación española (Piza, 2011), procedimientos masivos de identificación de omisos, corrección de errores y en la comprobación de valores que implican hechos objetivos, que si bien entrañan una disputa, el núcleo de la diferencia es más objetivo y da lugar a la aceptación o a la liquidación oficial dentro de acciones que buscan el cumplimiento de las obligaciones fiscales para cada caso seleccionado.

Las acciones de control extensivo, teniendo en cuenta el alto volumen de contribuyentes y el universo de declaraciones en 2011-2016, han venido ganando terreno en el margen de acción del control tributario en la DIAN, teniendo en cuenta los resultados ob- tenidos con su ejecución. No obstante, no se han desarrollado procedimientos de control extensivo formalmente considerados dentro del proceso de fiscalización.

Sin embargo, el grueso de la gestión de fiscalización tributaria en la DIAN y sus resultados se dan con las acciones de control intensivo, verificando el cumplimiento de las obligaciones fiscales con el fin de establecer la correcta aplicación de las normas previstas para cada caso seleccionado, por lo que las acciones se dirigen particularmente a un sujeto, sea persona jurídica o natural, generándose una controversia de mayor profundidad en los hechos, las pruebas, y en la aplicación de las normas (Piza, 2011), donde estas actividades se cobijan dentro del proceso oficial de Fiscalización y Liquidación de la DIAN, encontrando dentro de este proceso, un subproceso denominado "Control Tributario", en el cual se ejecuta el grueso de la fiscalización tributaria propiamente dicha mediante la ejecución de tres procedimientos, a saber:

i) Investigación de Obligaciones Tributarias Sustanciales y Formales, donde se realizan las investigaciones pertinentes con el objeto de controlar el cumplimiento de las obligaciones sustanciales y formales a cargo de los contribuyentes, para proponer la determinación oficial de la obligación tributaria sustancial y/o formal y/o la sanción cuando fuere el caso; 
ii) Determinación Oficial de Impuestos, para proferir actos definitivos, encaminados a establecer la exactitud del tributo y el debido cumplimiento de la obligación tributaria sustancial;

iii) Imposición de Sanciones Tributarias, para determinar la procedencia de imponer sanciones independientes a los contribuyentes o entes que incurran en hechos sancionables, con el fin de controlar el cumplimiento de las obligaciones formales.

No obstante, antes del desarrollo de estos procedimientos, hay una labor fundamental adelantada por parte de la Coordinación de Programas de Control y Facilitación de la Subdirección de Gestión de Análisis Operacional de la DIAN, que con base en la diferente información con que se cuenta para desarrollar el control tributario, con fundamento en el artículo $6^{\circ}$ de la Resolución 2546 del 19 de marzo de 2010, que modifica el Artículo 25 de la Resolución No. 11 del 4 de noviembre de 2008, modificado por el Artículo $2^{\circ}$ de la Resolución 4105 de 2009 , aplica metodologías para determinar los focos de evasión y contrabando; formula, diseña, elabora y documenta los programas y campañas de control; y selecciona los casos específicos que deben ser objeto de los mismos (entre otras funciones), insumo que le suministra a la Subdirección de Gestión de Fiscalización Tributaria, que a su vez lo canaliza a las diferentes dependencias de Fiscalización del Nivel Local (Direcciones Seccionales), quienes ejecutan y operativizan mediante investigaciones los programas de control tributario intensivo, que se refieren a determinadas conductas tributarias y se aplican conforme a los parámetros de un programa de fiscalización en específico.

A su vez, se ha implementado un Manual de Lineamientos de Fiscalización (DIAN, 2013), que detalla los principales elementos del proceso en cuanto al flujo de actividades de la fiscalización tributaria, desde que se determinan los seleccionados por parte de la Coordinación de Programas de Facilitación y Control hasta el detalle de cómo fluyen los insumos hasta que se desarrollan las acciones de control intensivo de la fiscalización tributaria, dando un alto nivel de detalle al desarrollo de la investigación tributaria tanto de determinación oficial de impuestos como de imposición de sanciones, incluyendo algunos aspectos procedimentales como el régimen probatorio, obligaciones tributarias formales y sustanciales, y unos lineamientos del análisis contable.

\section{Instrumentos gerenciales y de} planeación del control tributario para contrarrestar la evasión tributaria

\section{i. Plan Estratégico 2014-2018}

El Plan Estratégico es el instrumento mediante el cual la autoridad tributaria nacional se plantea el alcance de sus objetivos a mediano y largo plazo, los cuales están estrechamente ligados a los grandes objetivos del Plan Nacional de Desarrollo del Gobierno Central, centrándose en el fomento a la competitividad de la economía nacional, el incremento del cumplimiento voluntario de las obligaciones tributarias, aduaneras y cambiarias, y el apoyo a la sostenibilidad financiera del país. 
En el Plan estratégico 2014-2018 vigente, se proponen cuatro objetivos estratégicos, así:

Como primer objetivo, se formula la contribución "a la sostenibilidad de las finanzas públicas del Estado colombiano", cumpliendo las metas de recaudo con eficiencia y eficacia, manteniendo el dinamismo del recaudo como porcentaje del PIB.

En un primer lugar, si bien se encuentra positivo que se haya propuesto un incremento del recaudo tributario con el mismo dinamismo a como se incrementa el PIB, como se vio del comparativo del recaudo tributario de renta y renta CREE de los años 2014-2016 frente al crecimiento del PIB, el recaudo no refleja la tendencia de incremento que presenta el PIB.

Por otra parte, si bien se encuentra favorable que se establezca dicho incremento en el recaudo tributario dentro de la planeación de 2014-2018, no se encontraron definidos instrumentos de medición, control y evaluación que materializaran dicho propósito.

Como segundo objetivo estratégico, se previó "aportar al mejoramiento de la competitividad del país", centrándose en la consolidación de un sistema aduanero moderno que incorpore las normas y mejores prácticas internacionales, entre otros aspectos no relacionados con la evasión tributaria (por lo que no se profundizará sobre el particular).

\section{El fomento al cumplimiento voluntario de} las obligaciones tributarias, aduaneras y cambiarias se estableció como tercer objetivo estratégico, dentro del cual se propende al fortalecimiento de la cultura tributaria, la ejecución de acciones integrales de servicio y control para disminuir los costos de cumplimiento al ciudadano-cliente y los costos de operación de la entidad, promoviendo la cultura de la legalidad y generando riesgo subjetivo a quien persiste en el incumplimiento de sus obligaciones fiscales.

No obstante la importancia que reviste el concepto de riesgo subjetivo para la DIAN, resulta paradójico que en los últimos años se haya incluido dentro de las reformas tributarias algunos privilegios con carácter de amnistía que buscan beneficiar a quienes incumplen sus obligaciones fiscales desincentivando a los contribuyentes cumplidos, que no ven en su esfuerzo de cumplimiento fiscal un estímulo que si se traslada al incumplido, aspecto que afecta directa y desfavorablemente este propósito convertido en objetivo estratégico de "Fomentar el cumplimiento de las obligaciones tributarias, aduaneras y cambiarias", ya que si bien estas amnistías fiscales traen consigo réditos a corto plazo por favorecer el cumplimiento de metas de recaudo del año actual y disminuir los inventarios de cartera existente, a mediano y largo plazo presentan unos efectos negativos en cuanto a la llamada "cultura de la contribución" y el cumplimiento voluntario de las obligaciones fiscales.

Ahora bien, dentro de este objetivo estratégico se fijó una meta de ampliación de la base de contribuyentes del impuesto sobre la renta que podría resultar insuficiente, si se tiene en cuenta que conforme a las estadísticas de la Subdirección de Gestión de Asistencia al Cliente de la DIAN (2017), para el año 2016 se encontraban inscritos con la responsabilidad de presentar declaración de renta y complementarios un total de 
4.113.914 contribuyentes, donde mediante el ejercicio de cruces y análisis de la información exógena y otra disponible, mediante acciones de fiscalización y control extensivo se podrían llegar a determinar un mayor número de omisos del impuesto sobre la renta, ampliando así la base existente.

Por último, se contempló un cuarto objetivo estratégico relacionado con "Desarrollar las mejores prácticas de la gestión de Buen Gobierno para incrementar los niveles de confianza y credibilidad", que se enmarca en lograr avances en la gestión administrativa en aspectos como el logro de altos niveles de confianza y credibilidad en la ciudadanía mediante la implementación de las mejores prácticas de la gestión pública (buen gobierno) mejorando la eficiencia, transparencia y rendición de cuentas, aspecto sobre el cual no se profundizará en el presente trabajo.

Así las cosas, de estos objetivos estratégicos se desprenden los objetivos tácticos, que exclusivamente en lo relacionado con el control y fiscalización del orden tributario se enmarcan en lo siguiente:

\section{ii. Plan táctico}

El Plan Táctico representa una desagregación de los objetivos estratégicos, los cuales se descomponen mediante iniciativas tácticas que vienen a ser actividades realizables y con indicadores medibles que involucran a responsables específicos dentro de todas las áreas de la DIAN, asignando metas específicas tanto cuantitativas como cualitativas, tiempos, recursos, seguimiento y medición mediante indicadores, entre otros elementos que vendrían a ser los que hacen materializar lo que se contempla en la planeación.
Dicho plan está compuesto por un total de 16 objetivos tácticos, de los cuales solo se hará referencia a tres (3), que son los que se encuentran relacionados en una mayor medida con el control y la fiscalización tributaria, así:

a) Acciones integrales e innovadoras de control y fiscalización para reducir la evasión

El objetivo táctico que se considera más importante desde el punto de vista del control y la fiscalización tributaria es el que se denomina “GM3. Realizar acciones integrales e innovadoras de control y fiscalización para reducir la evasión, la elusión y el contrabando", en el cual se han establecido tres iniciativas, a saber:

Se encuentra la de: i) Construir líneas de acción de fiscalización que garanticen la implementación de programas efectivos de control tributario, aduanero, cambiario e internacional (TACI), basados en la segmentación de clientes, considerando las operaciones internacionales, los precios de transferencia y la posible erosión de las bases tributarias, identificando nuevos nichos de evasores u omisos.

No obstante, dentro de las iniciativas que desarrollan este punto, no se encuentran acciones concretas donde el mismo se materialice. Lo único que se encuentra es la creación reciente de la "Coordinación Integral de Lucha contra el Contrabando y la Evasión Tributaria" mediante Resolución 134 del 22 de diciembre de 2015 en el Despacho de la Dirección de Gestión de Fiscalización, la cual se encargará de coordinar y ejecutar las visitas integrales TACI, mas no se definen 
actividades o acciones con las que se promueva el diseño de programas innovadores de fiscalización, solo haciéndose referencia al diseño convencional de programas de control y facilitación, donde se indica la existencia de limitaciones en términos de recursos humanos.

Dentro de este objetivo se incluye otra iniciativa relacionada con ii) Controlar el cumplimiento de las obligaciones TACI de grupos económicos, cadenas productivas, redes empresariales y de diversas formas de vinculación empresarial para reducir la elusión y la evasión, donde de igual manera que en el punto anterior, no se desprenden de forma concreta las actividades y objetivos que van a materializar o a hacer efectivo este aspecto que se considera plenamente trascendental para realizar un control tributario eficaz, donde, igual que el anterior, se pretende diseñar programas innovadores, más las iniciativas, recursos y acciones concretas no se salen de lo tradicionalmente establecido.

Frente a las iniciativas relacionadas con el control a las operaciones internacionales, los precios de transferencia y la posible erosión de las bases identificando nuevos nichos de evasores u omisos, llama la atención que dichas competencias a cargo de la Subdirección de Gestión de Fiscalización Internacional, en esta área se pasó de 137 funcionarios en 2010 a 87 en el 2015 (DIAN, 2015), reduciendo así su capacidad operativa, sin entenderse cómo con menos recursos se van a identificar más obligados, evasores u omisos, máxime cuando las disposiciones del Régimen de Precios de Transferencia contempladas en la Ley 1819 del 29 de diciembre de 2016 amplían la base de sujetos obligados a cumplir las disposiciones de este régimen, incrementándose así normativamente el alcance del control, pero en la realidad se reduce la capacidad operativa para ejercerlo.

Se prevén otras actividades referentes a: iii) Adelantar proyectos estratégicos como la implementación de las NIIF, la auditoría forense y la factura electrónica, así como mediciones de evasión tributaria, contrabando y gasto tributario con estándares internacionales, que permitan realizar el seguimiento a las metas de gobierno y al propio desempeño misional, donde sobre este punto sí se desprenden iniciativas tácticas concretas, pero se dejan salvedades en relación con el déficit de funcionarios y ausencia de expertos técnicos sobre los temas, sin que se derive, proponga o estime desde este instrumento que se van a asignar los recursos necesarios para adelantarlos, llevándolos a cabo en forma exitosa, y lo que de igual forma, a la fecha de realización del presente trabajo (julio de 2017), no se han convertido en realidad tales iniciativas.

Sobre el tema particular de la adopción de las Normas Internacionales de Información Financiera (NIIF) que se crearon como estándares internacionales a fin de uniformar y hacer mundialmente aceptadas y comprensibles las normas y la información contable, el Artículo 137 de la Ley 1819 del 29 de diciembre de 2016 señaló la fijación mediante reglamento de un sistema de control o de conciliaciones de las diferencias que surjan entre la aplicación de los nuevos marcos técnicos normativos contables con las normas tributarias aplicables, reglamentación a cargo del Gobierno Nacional, que ya habiendo pasado el primer semestre del año 2017 no se ha dado, y teniendo en cuenta el alto volumen de diferencias conceptuales de las 
NIIF de cara a las normas fiscales, dicha demora afecta gravemente la seguridad jurídica en la determinación de las bases fiscales de la información financiera que bajo NIIF posean los obligados para la presente vigencia 2017.

En ese orden de ideas, se encuentra que frente a las reiteradas críticas realizadas al control y la fiscalización tributaria referentes a que los programas y las campañas de control se enfocan tradicionalmente en los mismos aspectos sin que se diseñen metodologías que promuevan el diseño de programas innovadores y que identifiquen prácticas sofisticadas de evasión de difícil detección, si bien desde la planeación se define este objetivo, no se encuentra que dichos propósitos sean desplegados en aspectos concretos convertidos en iniciativas tácticas, siendo difícil conseguir resultados diferentes cuando en la práctica se va a hacer lo mismo de siempre. Más aún, si se han identificado problemas como la falta de oportunidad en la reglamentación de reformas tributarias, insuficiente recurso humano, la ausencia de expertos técnicos y la carencia de información de calidad, sin que se definan elementos donde se establezca que se toman las medidas que contrarresten las dificultades y los efectos de estos problemas a fin de proveer soluciones oportunas, siendo así muy difícil que se logren los cambios requeridos en el control tributario para la reducción de la evasión atendiendo adecuadamente las actividades necesarias para modernizar la fiscalización tributaria con metodologías innovadoras, información e insumos conducentes y los recursos tecnológicos y humanos que desarrollen los análisis que permitan identificar los focos gruesos de la evasión y los modelos sofisticados de difícil detección. b) Acuerdos de cooperación e intercambio de información con incidencia tributaria y aduanera

Dentro del primer objetivo estratégico se plantea otro objetivo táctico relacionado con el control tributario, que se denomina "GM6. Cumplir con los acuerdos de cooperación e intercambio de información suscritos por la entidad y los compromisos derivados de los Tratados y Acuerdos con incidencia tributaria y aduanera", que, desprendido en sus iniciativas y acciones específicas, solo se refiere a la suscripción de convenios de cooperación y/o de intercambio de información en temas aduaneros y de comercio exterior, dejando por fuera la información con relevancia tributaria.

Este aspecto llama la atención, ya que la OCDE aboga por el intercambio de información entre las autoridades fiscales para contrarrestar la evasión tributaria (OCDE, 2009), y para el control a los impuestos corporativos cuando los sujetos obligados realizan operaciones internacionales es fundamental el intercambio de información con fines tributarios, por lo que no se entiende cómo, si desde el objetivo táctico “GM3” antes visto se acogen iniciativas relativas al control del cumplimiento de las obligaciones TACI de grupos económicos considerando las operaciones internacionales, los precios de transferencia y la posible erosión de las bases tributarias sobre el intercambio de información y suscripción de acuerdos de cooperación internacionales, se desestime su materialización por ausencia de definir acciones, recursos, responsables y medios de control sobre el particular, lo que le resta eficacia a la materialización de esta iniciativa. 
c) Profundizar en el conocimiento de los contribuyentes mediante técnicas de inteligencia de negocios y gestión de riesgos

Dentro del Objetivo estratégico tres (3), se encuentra un objetivo táctico, así: “GM8. Profundizar en el conocimiento sobre los usuarios y contribuyentes mediante técnicas de inteligencia de negocios y gestión de riesgos para fortalecer el servicio y desarrollar estrategias diferenciadas de control".

Bajo este objetivo, se pretende el rediseño e implementación del proyecto de inteligencia de negocios que permita generar tendencias de comportamiento fiscal con perfiles de riesgos nacionales y regionales que luego sustenten la definición de la estrategia de servicio y los programas de fiscalización y control, identificando tramos de evasión, fraude fiscal y contrabando.

Sin embargo, la DIAN no cuenta con un sistema de gestión de riesgos medianamente estructurado y funcional. Desde la reestructuración dada con el Decreto 4048 de 2008 y la Resolución No. 11 del 4 de noviembre del mismo año, se creó la Coordinación de Administración y Perfilamiento de Riesgos dependiente de la Subdirección de Gestión de Análisis Operacional, pero dicha área cuenta con déficit de personal para desarrollar funciones, sin que desde el punto de vista de perfilamiento del riesgo tributario se ejerza actividad o control alguno, el cual se limita a algunas labores de perfilamiento del riesgo aduanero. Adicionalmente, se carece de expertos técnicos sobre el tema, lo que impide que se materialicen estas iniciativas relativas a desarrollar la fiscalización tributaria mediante un sistema de control basado en la gestión de riesgos con el perfilamiento de contribuyentes, más aún cuando no se abre el espacio requerido en cuanto a la asignación de los recursos técnicos, humanos, y de información idóneos, necesarios y competentes, para el desarrollo de tal iniciativa.

No obstante lo anterior, se destaca que dentro de este objetivo se han desagregado iniciativas relacionadas con la segmentación y caracterización de contribuyentes, y elaboración de estudios y análisis focalizados a infracciones TACI, con el fin de contribuir al control de las obligaciones; y a adelantar un estudio que formule propuestas y estrategias para el control de la evasión de los impuestos indirectos al consumo en el período 20162018. Sin embargo, se plasman los mismos problemas de los anteriores puntos, relativos al insuficiente recurso humano, la ausencia de expertos técnicos en la materia y la carencia de información de calidad.

Finalmente, cabe precisar a manera de conclusión de lo anteriormente expuesto, que el éxito de los instrumentos de planeación radica en que a partir de lo planeado se determinen de manera concreta las acciones, responsables, tiempos, recursos, factores de éxito, seguimiento y medición mediante indicadores, entre otros elementos para controlar que lo planeado se ejecute, lo que, de manera general, no se definió para algunos aspectos de los tres objetivos tácticos planteados.

Lo anterior, ya que existe la probabilidad de que, si lo planeado no se despliega mediante asignación de responsables, recursos, seguimiento, controles y alertas respectivas, puede convertirse en meras expectativas y documentos, mas no sea materializado en la realidad operativa de la fiscalización tributaria, o bien puede que queden cumplidas las 
acciones planeadas en el papel pero sin verse los resultados en la realidad.

\section{Planes operativos de fiscalización - años} 2011-2016

El plan operativo de fiscalización es una herramienta gerencial donde convergen las políticas trazadas por las Subdirecciones de Gestión de Fiscalización Tributaria y la Subdirección de Gestión de Fiscalización Internacional del Nivel Central en coordinación con las actividades y acciones que ejecutan las Direcciones Seccionales, las cuales deben corresponder a los lineamientos gerenciales que para el período establezca la Dirección de Gestión de Fiscalización.

Este elemento en sí considerado es el principal instrumento de medición de los resultados de la operación del control tributario, ya que con este se miden, evalúan y controlan, mediante un cuadro de indicadores, las actividades de gestión desarrolladas en un periodo anual, así como los resultados obtenidos en desarrollo de la operación ${ }^{7}$, motivo por el cual este es uno de los principales elementos de control a evaluar en el presente análisis.
4. Proyectos de inversión relacionados con el fortalecimiento de la fiscalización tributaria años 2011-2016

El control tributario se coadyuva adicionalmente con financiación de recursos presupuestales de inversión mediante dos proyectos, los cuales se analizan a continuación:

\section{i. Proyecto de implantación del plan de choque contra la evasión}

Con el propósito de fortalecer la fiscalización tributaria y reducir las altas brechas de evasión existentes en los impuestos del orden nacional, la Ley 223 de 1995 creó el plan de choque, cuyos criterios se definirían mediante planes anuales financiados con recursos presupuestales de inversión, los cuales, conforme a lo dispuesto en la norma, comprenderían, en un primer lugar, la realización de programas de gestión y programas de control extensivo destinados prioritariamente al cumplimiento voluntario de las obligaciones tributarias, al control de omisos, de inexactos y de quienes no facturan, así como al control de ingresos y al establecimiento de índices de evasión.

\footnotetext{
${ }^{7}$ A manera de ejemplo, para el año 2015, se establecieron los siguientes objetivos: para las Direcciones Seccionales, quienes son las que desarrollan las labores operativas del proceso: realizar la Gestión de Fiscalización para alcanzar el objetivo recaudatorio (gestión como resultado de los actos proferidos por las divisiones de gestión de fiscalización y de liquidación a nivel nacional); evacuar los expedientes asignados y/o abiertos. Y para la Subdirección de Gestión de Fiscalización Tributaria, que tiene a cargo la función de superior técnico y jerárquico del proceso: presentar una propuesta de programas de acuerdo con el plan táctico; definir a los contribuyentes obligados a facturar electrónicamente; definir y adelantar las actividades requeridas para realizar 2 acciones masivas de control, y ejecutar las actividades requeridas para implementar el Servicio Informático de la Factura Electrónica.
} 
Señala la misma ley en un segundo lugar otro propósito relativo al adelantamiento de acciones de fiscalización de fondo (control intensivo), que se orientarían a determinar forzosamente las obligaciones de los que persisten en el incumplimiento después de haber sido detectados en los programas de gestión de control extensivo, y a la fiscalización de aquellos contribuyentes que evaden sus impuestos presentando inexactitud en sus declaraciones tributarias.

Así las cosas, a estos planes anuales a los que se les han destinado recursos desde la vigencia presupuestal 1998, dentro de los años 2011-2017, se ha asignado lo siguiente (véase cuadro 5):

Los anteriores recursos, en su gran mayoría, se han destinado a la vinculación de personal de carácter temporal, pero este personal no precisamente adelanta funciones en las áreas de control tributario y aduanero, desatendiéndose lo previsto en la norma, donde se establece que los recursos estarán destinados únicamente al control y/o fiscalización tributaria o aduanera (esta última, en los términos del Artículo 152 de la Ley 223 de 1995), ya que de los 1.853 funciona- rios vinculados con recursos de inversión de este plan, solo 536 desarrollan funciones de control tributario y aduanero (DIAN, 2016) ${ }^{8}$, que representan el $29 \%$ del total de vinculados con este presupuesto, donde los demás funcionarios realizan labores en otras áreas, tanto de apoyo, como misionales dentro de la entidad, pero diferentes a las áreas de fiscalización.

Llama la atención que, a pesar de que la Ley 223 de 1995 dispuso normas que dieron la oportunidad para fortalecer el control tributario y de modernización de la fiscalización a partir de algunas de sus disposiciones que otorgaron una destinación específica de recursos contra la evasión, dichos aspectos no se han visto en la realidad, toda vez que desde la vigencia de la misma hasta ahora se plantean las mismas necesidades de fortalecer la fiscalización tributaria y reducir las altas brechas de evasión existentes en los impuestos del orden nacional, situación que plantea dudas sobre si se llevará a la realidad la otra oportunidad de fortalecimiento del recurso humano técnico, calificado y suficiente con base en las nuevas disposiciones de la Parte "XIV Administración tributaria" de la Ley 1819 del 29 de diciembre de 2016 en la actualidad.

Cuadro 5. Recursos apropiados plan anual antievasión años 2011-2016 (en millones de pesos)

\begin{tabular}{|c|c|c|c|c|c|c|}
\hline $\mathbf{2 0 1 1}$ & $\mathbf{2 0 1 2}$ & $\mathbf{2 0 1 3}$ & $\mathbf{2 0 1 4}$ & $\mathbf{2 0 1 5}$ & $\mathbf{2 0 1 6}$ & $\mathbf{2 0 1 7}$ \\
\hline$\$ 321.991,77$ & $\$ 331.651,52$ & $\$ 150.866,98$ & $\$ 148.210,01$ & $\$ 163.958,22$ & $\$ 185.559,90$ & $\$ 204.234,72$ \\
\hline
\end{tabular}

Fuente: Información presupuestal DIAN.

${ }^{8}$ Se registran solo 536 funcionarios de planta temporal vinculados con recursos del plan, ubicados en áreas de fiscalización (tanto del nivel central como del nivel local, y en fiscalización tributaria como aduanera). 
ii. Proyecto de inversión para la implementación, impulso y masificación de la factura electrónica en Colombia

Como un mecanismo para controlar la evasión tributaria e incrementar la competitividad de las empresas colombianas a nivel internacional, se estableció, mediante Decreto 2242 de 2015 , el reglamento de las condiciones de expedición e interoperabilidad de la factura electrónica con fines de masificación y control fiscal, donde dicho proyecto, que se financia con recursos de Banca Multilateral (Banco Interamericano de Desarrollo) se inició desde el año 2015, y en 2018 debe estar en funcionamiento.

De acuerdo con la programación prevista y las recomendaciones recibidas de la asesoría técnica prestada por el CIAT, su plataforma tecnológica deberá ser adquirida en el año 2017-2018, que es cuando se inicia su puesta en funcionamiento, y hasta ahora los recursos asignados se han destinado para la adquisición de servidores y la asesoría técnica, consultoría y gerencia del proyecto.

No obstante, de acuerdo con las recomendaciones de la comisión de expertos para la equidad y la competitividad tributaria plasmadas en su informe final de diciembre de 2015, el desarrollo de la factura electrónica en Colombia es muy bajo, cuando entre 2011 y 2015 varios gobiernos de América Latina han promovido su uso como una forma de lucha contra la evasión, pasando de registrar niveles bajos de desarrollo en materia de penetración de la factura electrónica a tener niveles similares a los de países desarrollados, y algunos países como Brasil están a la vanguardia en el mundo.
Así mismo, señala este mismo informe (2015) que toda vez que la lista de bienes excluidos y exentos de IVA en Colombia es más amplia que en los estándares internacionales, la complejidad del tributo dificulta su administración, lo cual se agrava por el rezago que muestra el país en materia de implementación de la factura electrónica, donde Colombia muestra avances francamente precarios en la materia, comparativamente con los fuertes esfuerzos evidenciados en países de la región.

En el año 2017, en el desarrollo de este proyecto, se han redefinido varias actividades desde el punto de vista de desarrollo de ingeniería de detalle y del software debido a recomendaciones de la consultoría del CIAT, lo que ha requerido la realización de actividades no previstas en la formulación inicial del Proyecto y que postergan su finalización, esperada para este mismo año (DIAN, 2017).

Dicho retardo en la implementación de la factura electrónica dificulta el cumplimiento de las metas estipuladas en el plan estratégico DIAN 2014-2018, donde se espera reducir la tasa de evasión del IVA, partiendo de una línea base en 2014 del $23 \%$, al $21 \%$ en 2015; al $18 \%$ en 2016; al $15 \%$ en 2017 y al $11 \%$ en 2018 , toda vez que si se habla de finalización del proyecto en 2018, su producción se da completamente hasta 2019, y no se contaría con esta herramienta de fiscalización para cumplir con los objetivos definidos en este Plan Estratégico, cuya vigencia culmina en 2018, a fin de disminuir las altas tasas de evasión presentadas en el país en el impuesto a las ventas, lo que permitiría inferir que la evasión en IVA conservaría la misma tendencia al incremento observada conforme a los análisis antes presentados, que a pesar de que 
los cálculos oficiales la ubican en $23 \%$ para 2014, otros análisis la sitúan en el doble del nivel calculado oficialmente.

Como conclusión de lo antes expuesto, se puede indicar que a pesar de que la DIAN cuenta con instrumentos de planeación, operación, gestión, medición y evaluación del control tributario, así como se han definido objetivos para modernizar la fiscalización y se han asignado recursos de inversión con los que se ha pretendido mejorar los resultados del proceso, en la práctica, debido al mantenimiento de las tendencias de las tasas de evasión en los mismos márgenes en los años 2011-2016 en los términos indicados en párrafos precedentes, se puede observar que los avances han sido insuficientes en la materia, y la gestión de fiscalización no ha contribuido a ejercer presión fiscal sobre esta tendencia, máxime si sobre dichos propósitos no se han desprendido y no se han adelantado acciones y actividades eficaces, y no se han asignado los recursos humanos técnicos calificados y suficientes que materialicen su ejecución y hagan realizable la necesaria modernización $\mathrm{y}$ fortalecimiento del control tributario.

Una vez expuestos los principales instrumentos de la planeación, gestión, medición y evaluación del control tributario que ejerce la DIAN, se pasará seguidamente a analizar los resultados de la medición de las actividades de la fiscalización tributaria, partiendo de las cifras de la gestión de los últimos años a nivel nacional, desarrollando así el tema central del presente trabajo que se enmarca en analizar los elementos de control y medición de la fiscalización tributaria, así como los resultados que arroja la gestión efectiva de fiscalización y los programas de control intensivo como elementos de la gestión de fiscalización tributaria contra la evasión de los impuestos nacionales para los años 2011-2016.

\section{La medición del control tributario con base en la meta de gestión efectiva de fiscalización para los años 2011-2016}

En este punto, corresponde un análisis de los resultados de la medición de la gestión de fiscalización tributaria con base en las cifras que recopila y consolida la Coordinación de Planeación y Evaluación de la DIAN, así como un comparativo entre las metas fijadas y las proyecciones de evasión, para determinar si la fijación de metas coincide con alguna tendencia o parámetro resultante del cálculo de las proyecciones de evasión o si en alguna medida las metas le apuntan a contrarrestar las estimaciones o están determinadas de acuerdo con su comportamiento.

Por otra parte, se realizará un análisis crítico a los programas de fiscalización y la labor de control intensivo desarrollada por la DIAN y su alcance frente al universo de contribuyentes y declaraciones, examinando algunas actividades que le generan desgaste al proceso, pasando a observar si el control tributario y el ejercicio de la fiscalización se evalúa de alguna medida consistentemente con el recaudo de los valores de tributos determinados y las sanciones impuestas y/o su control de legalidad, o si los análisis se limitan a la producción de actos oficiales.

\section{A. Análisis de los resultados de la gestión efectiva de la fiscalización tributaria para los años 2011-2016}

El instrumento de mayor importancia con el que se miden los resultados de la gestión operativa desarrollada dentro del proceso 
de fiscalización tributaria está dado por lo que se denomina como "la gestión efectiva de fiscalización", que se define en su plan operativo como correcciones y presentación de declaraciones, sanciones y liquidaciones oficiales ejecutoriadas y no ejecutoriadas, gestión perceptiva y gestión por menor pérdida líquida (DIAN, 2013), entre otros.

Así las cosas, se encuentra que el principal instrumento de medición del proceso está dado por un valor donde se individualiza para cada una de las Direcciones Seccionales (nivel local y estrictamente operativo) una meta individual, la cual corresponde a una suma dineraria que dentro del desarrollo de sus facultades de fiscalización e investigación debe estar respaldada con la expedición de actos oficiales de determinación de impuestos y sanciones con ocasión de correcciones y presentación de declaraciones, y otros actos por medio de los cuales se imponen sanciones que se encuentren asociadas a un tributo o sean independientes, así se encuentren ejecutoriados o no ejecutoriados, donde lo importante es que dicho valor se encuentre amparado por actos oficiales o preparatorios individualizados a cargo de contribuyentes, proferidos por las diferentes áreas de fiscalización y liquidación.
Dentro del periodo de enero de 2011 a 2016, se han establecido metas de gestión efectiva que suman un total de $\$ 14,417$ billones de pesos, y cuyos resultados de gestión (actos ejecutoriados y no ejecutoriados) han arrojado las siguientes cifras (DIAN, 2017) (véase cuadro 6).

Así las cosas, en la gestión operativa del control tributario se ha sobrecumplido dicha meta establecida en el periodo de enero de 2011 a diciembre de 2016 en un 159,2\%, toda vez que se han proferido actos oficiales ejecutoriados y no ejecutoriados que respaldan sumas por $\$ 22,95$ billones cuando la meta se ha fijado en $\$ 14,41$ billones, resultados que para el año 2016 reflejan un alto sobrecumplimiento.

Este comportamiento podría evidenciar desde un punto de vista general una gestión exitosa. No obstante, podría reflejar una fijación de un valor insuficiente de las metas por subestimación del alcance de la productividad real del control tributario institucional; o que las metas no se determinan con base en estimaciones reales de las tasas de evasión impositiva; o una forma inadecuada de medir los resultados del proceso, ya que se limita a medir valores de producción de actos oficia-

Cuadro 6. Resultados de cumplimiento metas gestión efectiva fiscalización años 2011-2016

\begin{tabular}{|l|c|c|c|c|c|c|c|}
\hline \multicolumn{1}{|c|}{ Concepto/Año } & $\mathbf{2 0 1 1}$ & $\mathbf{2 0 1 2}$ & $\mathbf{2 0 1 3}$ & $\mathbf{2 0 1 4}$ & $\mathbf{2 0 1 5}$ & $\mathbf{2 0 1 6}$ & $\begin{array}{c}\text { Total } \\
\text { periodo } \\
\text { analizado }\end{array}$ \\
\hline $\begin{array}{l}\text { Valor meta establecida } \\
\text { (en millones \$\$) }\end{array}$ & 1.250 .000 & 1.385 .700 & 1.581 .300 & 3.100 .000 & 3.500 .000 & 3.600 .000 & 14.417 .000 \\
\hline $\begin{array}{l}\text { Valor resultado de cumpli- } \\
\text { miento (en millones \$\$) }\end{array}$ & 1.383 .081 & 2.065 .945 & 4.423 .461 & 4.408 .190 & 3.763 .865 & 6.907 .392 & 22.951 .934 \\
\hline $\begin{array}{l}\text { Porcentaje cumplimien- } \\
\text { to meta }\end{array}$ & $\mathbf{1 1 0 , 6 5} \%$ & $\mathbf{1 4 9 , 0 9 \%}$ & $\mathbf{2 7 9 , 7 4 \%}$ & $\mathbf{1 4 2 , 2 0 \%}$ & $\mathbf{1 0 7 , 5 4} \%$ & $191,87 \%$ & $159,20 \%$ \\
\hline
\end{tabular}

Fuente: Coordinación de Planeación y Evaluación DIAN - Resultados planes operativos 2011-2016. 
les per se ejecutoriados y no ejecutoriados, sin un control de legalidad o calidad externo $\mathrm{o}$ independiente.

La tendencia en los resultados de los valores representados en actos oficiales expedidos en los años analizados (gestión efectiva) frente a las metas que se fijan, presenta sobrecumplimiento, acentuándose un comportamiento altamente distorsionado en el año $2013(279,74 \%)$ y en el último de análisis que corresponde a $2016(191,87 \%)$, y en los años 2012, 2014 y 2015, altamente superiores (véase gráfico 1).

Valga decir que respecto a estos sobrecumplimientos generalizados en las metas de gestión efectiva de fiscalización con base en esta forma de medir los resultados, incluyendo actos ejecutoriados y no ejecutoriados sin control de legalidad alguno y/o sin medición correlativa de los mismos en términos de recaudo de cara al anotado incremento en el comportamiento de las tasas de evasión, la Administración no haya replanteado la forma de medir los resultados de la gestión de este proceso y, contrariamente, este indicador se mantiene en la actualidad (2017) desde vigencias anteriores a las analizadas y se ha constituido como el elemento por excelencia y más importante para evaluar la gestión de fiscalización.

Si se parte de que los indicadores y las metas están bien definidas y los resultados se dan por una "eficiencia excesiva" mas no por una inadecuada formulación de los instrumentos de medición y evaluación del control tributario, se podría ver afectada la gestión real en sí misma, porque en la fijación de las metas del control tributario no se establecerían elementos que encaminen y dirijan la gestión a contrarrestar efectivamente la evasión, al entender cumplido el propósito del control tributario con una simple expedición de actos de fiscalización y liquidación.

Es importante que se analice si con la simple producción de actos oficiales se puede considerar reducida la evasión, o si para con-

Gráfico 1. Resultados de cumplimiento metas gestión efectiva fiscalización años 2011 al 2015

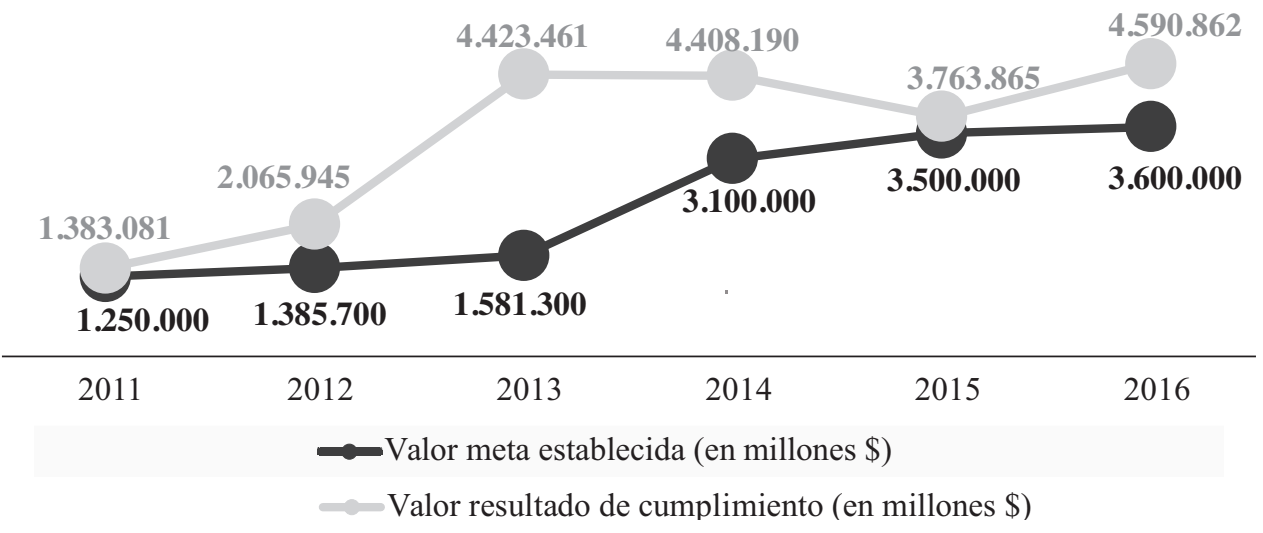

Fuente: Coordinación de Planeación y Evaluación DIAN - Resultados planes operativos de 2011 a 2016. 
siderar la verdadera efectividad del régimen sancionatorio tributario se debe medir si dichos papeles puestos en un filtro de legalidad son válidos, y en consecuencia convertibles en recursos donde efectivamente se pueda decir que se está contrarrestando la evasión, ya que lo que se pierde con la evasión tributaria son recursos dinerarios, por lo que se debería medir es la recuperación de los mismos, más no una mera producción de actos.

De igual forma, es fundamental que los programas y las investigaciones se diseñen e inicien sobre los sectores, prácticas y contribuyentes debidamente perfilados, cuyos análisis señalen que son quienes incurren en estas prácticas en mayor medida, pero como ya se advirtió, a pesar de existir una iniciativa institucional al respecto, documentada en un objetivo táctico relacionado con: "GM8. Profundizar en el conocimiento sobre los usuarios y contribuyentes mediante técnicas de inteligencia de negocios y gestión de riesgos para fortalecer el servicio y desarrollar estrategias diferenciadas de control", teniendo en cuenta las debilidades institucionales sobre estos temas por la ausencia de expertos técnicos para implementar un sistema de control basado en la gestión de riesgos con el perfilamiento de contribuyentes, sin abrirse el espacio requerido en cuanto a la asignación de los recursos técnicos, humanos, y de información idóneos, necesarios y competentes, resulta imposible de materializar tal iniciativa.
A continuación, se analizarán estos cumplimientos de gestión efectiva frente a las proyecciones de evasión realizadas oficialmente.

\section{Las metas de gestión efectiva de}

fiscalización frente a las proyecciones de evasión tributaria para los años 2010-2013 $(\text { DIAN, 2017) })^{9}$.

Con el fin de determinar si la fijación de las metas de gestión efectiva de fiscalización en materia tributaria se dirigen $u$ orientan a fin de contrarrestar o reducir los valores de evasión tributaria, donde se podría determinar que los insumos resultantes de los cálculos de evasión son utilizados para la toma de decisiones en la determinación de las metas de gestión efectiva, a continuación se hace un comparativo de las estimaciones de proyección de evasión tributaria frente a las metas fijadas de gestión efectiva de fiscalización (véase cuadro 7).

Comparadas las cifras anteriores, se observa que las proyecciones de evasión en renta jurídicas y en IVA señalan que para los años 2010-2013, esta se ubica entre $\$ 23$ y $\$ 26,9$ billones, y las metas de gestión efectiva de fiscalización se establecieron en $\$ 1,25$ a $\$ 3,1$ billones, donde si bien las metas, así como los cálculos de evasión, se incrementan, los mayores valores de metas de los años analizados (con excepción del año 2013) se mantienen relativamente constantes, encontrándose que el cumplimiento de la gestión efectiva de fis-

\footnotetext{
${ }^{9}$ A pesar de las limitaciones en la disponibilidad en la información de cálculos de evasión tributaria, toda vez que datan de vigencias anteriores en los términos señalados en apartes anteriores, se considera importante realizar este ejercicio de comparación de las metas de gestión efectiva de fiscalización en contraste con los valores de evasión efectuados según estimaciones oficiales, toda vez que se considera necesario analizar si la fijación de estas metas de gestión efectiva de fiscalización parte, o tiene como insumo, algún cálculo de evasión o los comportamientos de evasión tributaria que se presentan en el país, a efectos de determinar los alcances de la gestión.
} 
Cuadro 7. Proyecciones de evasión en renta personas jurídicas más impuesto a las ventas frente a las metas de gestión efectiva fijadas años 2010-2013

\begin{tabular}{|l|c|c|c|c|}
\hline \multicolumn{1}{|c|}{ Descripción concepto/año } & \multicolumn{3}{|c|}{ Cifras en billones de pesos (\$) } \\
\cline { 2 - 5 } & $\mathbf{2 0 1 0}$ & $\mathbf{2 0 1 1}$ & $\mathbf{2 0 1 2}$ & $\mathbf{2 0 1 3}$ \\
\hline $\begin{array}{l}\text { 1. Valores proyectados de evasión renta personas jurídicas (en bi- } \\
\text { llones de \$) }\end{array}$ & 14,468 & 14,926 & 15,133 & 13,182 \\
\hline 2. Valores evasión iva (en billones de \$) & 10,425 & 11,011 & 11,85 & 9,82 \\
\hline $\begin{array}{l}\text { Valores calculados de evasión en renta personas jurídicas más } \\
\text { impuesto a las ventas (1.+ 2.) }\end{array}$ & $\mathbf{2 4 , 8 9 3}$ & $\mathbf{2 5 , 9 3 7}$ & $\mathbf{2 6 , 9 8 3}$ & $\mathbf{2 3 , 0 0 2}$ \\
\hline $\begin{array}{l}\text { Metas fijadas gestión efectiva fiscalización en el año siguiente al que } \\
\text { se proyecta la evasión por estos dos conceptos }\end{array}$ & 1,25 & 1,3857 & 1,581 & 3,1 \\
\hline $\begin{array}{l}\text { Porcentaje de evasión proyectada a contrarrestar con gestión } \\
\text { de fiscalización }\end{array}$ & $\mathbf{5 , 0 2} \%$ & $\mathbf{5 , 3 4} \%$ & $\mathbf{5 , 8 6} \%$ & $\mathbf{1 3 , 4 8} \%$ \\
\hline
\end{tabular}

Fuente: Subdirección de Gestión de Análisis Operacional - Coordinación de Planeación y Evaluación - DIAN.

calización no ha producido una disminución o alteración alguna en los índices de evasión, y a pesar de que la evasión en IVA para el año 2013 presenta una disminución de un poco más de $\$ 2$ billones frente al año anterior, no se debe perder de vista que, como se señaló, otros análisis arrojan resultados que ubican la evasión en este impuesto en el doble de dichos estudios económicos oficiales, por lo que el cumplimiento de las metas no ha contribuido a disminuir la evasión, conforme a las cifras estimadas.

Si bien dentro del presente análisis no se pretende señalar que las metas de gestión efectiva de fiscalización se direccionen a contrarrestar en su totalidad los valores estimados de evasión, sí resultaría acertado que las metas fijadas cada vez redujeran las brechas de evasión existentes, donde se denote una tendencia progresiva a la disminución de la evasión impositiva.
Ahora bien, a continuación, se presentará la gestión de fiscalización en términos de programas e investigaciones realizadas, para de esta forma determinar si la gestión de fiscalización se ha intensificado o si se ha focalizado estratégicamente en aspectos específicos donde se produce en mayor medida la evasión tributaria.

\section{Análisis de las investigaciones de} fiscalización de los años 2011-2016

Por medio del diseño de programas es que se lleva a cabo y se materializa el control intensivo tributario a través del desarrollo de investigaciones de fiscalización, donde se particulariza una eventual conducta tributaria anormal incurrida por parte de un obligado tributario, y de allí, la Administración tributaria impulsa su operatividad para aplicar la norma mediante el desarrollo de un procedimiento tributario individualmente considerado, determinando oficialmente los tributos a que haya lugar e imponiendo las sanciones tributarias respectivas. 
Así las cosas, en el siguiente cuadro, se fiscalización abiertas por la DIAN ${ }^{10}$ a nivel presenta el número de investigaciones de nacional, entre los años 2010-2016:

Cuadro 8. Total investigaciones fiscalización tributaria abiertas años 2010-2016

\begin{tabular}{|c|c|c|c|c|c|c|}
\hline $\mathbf{2 0 1 0}$ & $\mathbf{2 0 1 1}$ & $\mathbf{2 0 1 2}$ & $\mathbf{2 0 1 3}$ & $\mathbf{2 0 1 4}$ & $\mathbf{2 0 1 5}$ & $\mathbf{2 0 1 6}$ \\
\hline 68.207 & 53.951 & 41.330 & 32.265 & 31.388 & 26.124 & 30.110 \\
\hline
\end{tabular}

Fuente: Coordinación de Gestión Operativa de la Subdirección de Gestión de Fiscalización Tributaria.

En consecuencia de las cifras anteriores, se denota una clara tendencia a disminuir el número de investigaciones de fiscalización (con excepción del año 2016) que, en últimas, es donde se desarrolla propiamente la labor operativa del control tributario. Dicha disminución hizo que se pasara de la realización de 68.207 en 2010 a 30.110 en 2016, presentándose un decremento del 55,85\% en el número de investigaciones dentro del periodo de análisis (véase gráfico 2).

Dicha situación surge por el mayor alcance que se les ha dado a las acciones de control tributario extensivo y perceptivo en 20112016 y a los resultados logrados en cuanto a los ya referidos sobrecumplimientos en las metas de gestión efectiva de fiscalización.

No obstante, el incremento de las acciones de control extensivo y perceptivo no debería conllevar consecuentemente a un decremento en las acciones de control intensivo, ya que como se analizó, son altas las tasas de evasión en el impuesto de renta y el impuesto a las ventas, y de igual forma, como se verá, se han incrementado el número de obligados en el impuesto de renta, de inscritos en Régimen Común, y se han creado más impuestos y obligaciones a controlar mediante reformas tributarias, hecho que refleja la necesidad de que dicho tipo de acciones deberían incre-

\section{Gráfico 2 Total investigaciones fiscalización tributaria abiertas años 2010 al 2016}

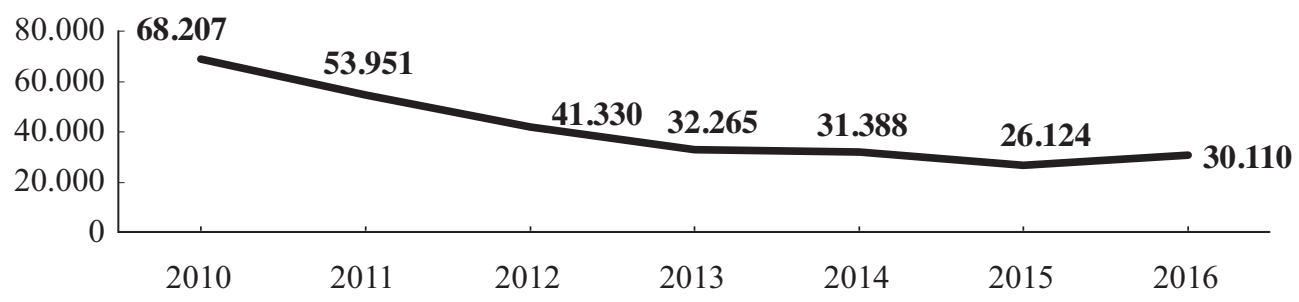

Total programas fiscalización tributaria abiertos años 2010 a 2016

Fuente: Coordinación de Gestión Operativa de la Subdirección de Gestión de Fiscalización Tributaria.

${ }^{10}$ Medidas en número de autos de apertura de fiscalización expedidos en las respectivas vigencias. 
mentarse. Máxime cuando las acciones de control intensivo coadyuvan en una mejor medida a fomentar la percepción del riesgo subjetivo en los sujetos obligados.

Se podría pensar que esta disminución en el número de investigaciones de fiscalización tributaria corresponde a una focalización en los grandes contribuyentes. No obstante, el número de investigaciones abiertas por la Dirección Seccional de Grandes Contribuyentes presenta la misma tendencia a la disminución (con la excepción anotada de las investigaciones abiertas en el año 2016), respecto al comportamiento antes visto del nivel nacional (véase cuadro 9).

Así las cosas, resulta llamativo que se disminuya el número de investigaciones de fiscalización tributaria desde el año 2010 al año 2016 en un $55,85 \%$, cuando el país presenta unos comportamientos de evasión tributaria altos comparativamente frente a países OCDE (OCDE, 2015), tendencia en evasión que no ha bajado la guardia, sino que, como se vio, tiende a incrementarse en valores absolutos y a mantenerse hasta el año 2016. Y adicionalmente, como ya se advirtió, hay cálculos de evasión extraoficiales que demuestran que el escenario parcial de evasión tributaria presentado por la DIAN puede llegar a ser más gravoso, por lo que debería intensificarse el control tributario mediante el diseño de programas y adelantamiento de investigaciones de fiscalización en vez de disminuirse, focalizando las acciones en determinados sectores de la economía, prácticas negociales, actividades económicas o en los contribuyentes que presenten mayores valores de evasión, que se identificarían a partir de un perfilamiento de riesgos que permita direccionar los esfuerzos donde más se desarrollan estas prácticas de evasión, sin que de esta forma se disminuya el número de investigaciones $\mathrm{y}$ acciones individualizadas, ya que de esta manera se desaprovecha la capacidad operativa del control tributario.

\section{i. Investigaciones de fiscalización por tipo de programa}

En los años 2010-2016, se han adelantado más de 150 tipos de programas de fiscalización desplegados en 283.375 investigaciones, las cuales, de acuerdo con el enfoque para el cual se establecieron, se pueden clasificar de la siguiente manera (véase cuadro 10).

\section{Cuadro 9. Dirección seccional de impuestos de grandes contribuyentes - productividad promedio esperada por investigación de fiscalización}

\begin{tabular}{|l|c|c|c|c|c|c|c|}
\hline \multicolumn{1}{|c|}{ Concepto / año } & $\mathbf{2 0 1 1}$ & $\mathbf{2 0 1 2}$ & $\mathbf{2 0 1 3}$ & $\mathbf{2 0 1 4}$ & $\mathbf{2 0 1 5}$ & $\mathbf{2 0 1 6}$ & Promedio \\
\hline $\begin{array}{l}\text { Número investigaciones fisca- } \\
\text { lización abiertas }\end{array}$ & 2568 & 2109 & 1496 & 1996 & 1320 & 1712 & $\mathbf{1 8 6 7}$ \\
\hline $\begin{array}{l}\text { Meta gestión cumplida (mi- } \\
\text { llones de \$) }\end{array}$ & 413.708 & 459.216 & 524.037 & 1.332 .721 & 1.480 .900 & 2.693 .000 & $\mathbf{1 1 5 0 5 9 7}$ \\
\hline $\begin{array}{l}\text { Productividad promedio } \\
\text { por investigación esperada } \\
\text { (millones de pesos) }\end{array}$ & $\mathbf{1 6 1 , 1 0}$ & $\mathbf{2 1 7 , 7 4}$ & $\mathbf{3 5 0 , 2 9}$ & $\mathbf{6 6 7 , 7 0}$ & $\mathbf{1 1 2 1 , 8 9}$ & $\mathbf{1 5 7 3 , 0 1}$ & $\mathbf{6 1 6 , 3 4}$ \\
\hline
\end{tabular}

Fuente: Coordinación de Gestión Operativa de la Subdirección de Gestión de Fiscalización Tributaria - Coordinación de Planeación y Evaluación Subdirección de Gestión de Análisis Operacional. 
Cuadro 10. Número de investigaciones fiscalización años 2010-2016 por clase de programa

\begin{tabular}{|l|c|c|c|c|c|c|c|c|c|}
\hline $\begin{array}{c}\text { Programa relacionado } \\
\text { con/año }\end{array}$ & $\mathbf{2 0 1 0}$ & $\mathbf{2 0 1 1}$ & $\mathbf{2 0 1 2}$ & $\mathbf{2 0 1 3}$ & $\mathbf{2 0 1 4}$ & $\mathbf{2 0 1 5}$ & $\mathbf{2 0 1 6}$ & Total & \% \\
\hline Declaraciones tributarias & 26.238 & 19.510 & 14.797 & 8.254 & 9.395 & 6.057 & 8.555 & 92.806 & 32,75 \\
\hline Devoluciones & 13.950 & 11.749 & 10.011 & 8.673 & 8.710 & 8.170 & 8.782 & 70.045 & 24,72 \\
\hline Sanciones independientes & 17.742 & 12.701 & 7.333 & 7.898 & 5.063 & 3.337 & 1.586 & 55.660 & 19,64 \\
\hline Solicitudes de corrección & 5.191 & 4.526 & 4.482 & 4.068 & 4.228 & 4.771 & $*$ & 27.266 & 9,62 \\
\hline Denuncias & 3.736 & 3.277 & 2.551 & 1.271 & 1.812 & 2.142 & 3.017 & 17.806 & 6,28 \\
\hline Otros & 1.350 & 2.188 & 2.156 & 2.101 & 2.180 & 1.647 & 8.170 & 19.792 & 6,98 \\
\hline Total & $\mathbf{6 8 . 2 0 7}$ & $\mathbf{5 3 . 9 5 1}$ & $\mathbf{4 1 . 3 3 0}$ & $\mathbf{3 2 . 2 6 5}$ & $\mathbf{3 1 . 3 8 8}$ & $\mathbf{2 6 . 1 2 4}$ & $\mathbf{3 0 . 1 1 0}$ & $\mathbf{2 8 3 . 3 7 5}$ & $\mathbf{1 0 0 , 0 0}$ \\
\hline
\end{tabular}

* Este número de investigaciones por 2016 hace parte de otros programas.

Fuente: Coordinación de Gestión Operativa de la Subdirección de Gestión de Fiscalización Tributaria.

Teniendo en cuenta el cuadro anterior, se observa que una tercera parte $(32,75 \%)$ de las investigaciones adelantadas en los años 2010-2016 se enfocaron en la fiscalización de declaraciones tributarias; una casi cuarta parte $(24,72 \%)$ estuvo relacionada con devoluciones de impuestos; casi una quinta parte $(19,64 \%)$, en imponer sanciones independientes; un 9,62\%, en solicitudes de corrección, y un 6,98\%, en diversos aspectos.

\section{a) Desgastes generados en la fiscalización} tributaria por otros procesos

Se encuentra que la capacidad operativa de la gestión de fiscalización se destina en más de la mitad a la determinación correcta de tributos en declaraciones tributarias y a la imposición de sanciones independientes por incumplimiento de obligaciones formales. No obstante, es llamativo que la cuarta parte de la fuerza de la fiscalización tributaria se destine a coadyuvar un proceso ajeno, que corresponde a las labores de Recaudación en la Gestión de las Compensaciones y Devoluciones, donde frente a los trámites abiertos con ocasión de solicitudes de devolución y/o compensación y los programas de fiscalización abiertos con este enfoque, se encuentra lo siguiente:

\section{Cuadro 11. Trámites compensaciones y/o devoluciones solicitadas frente a programas abiertos y derivados de este enfoque}

\begin{tabular}{|l|c|c|c|c|c|c|c|c|}
\hline \multicolumn{1}{|c|}{ No. solicitudes / año } & $\mathbf{2 0 1 0}$ & $\mathbf{2 0 1 1}$ & $\mathbf{2 0 1 2}$ & $\mathbf{2 0 1 3}$ & $\mathbf{2 0 1 4}$ & $\mathbf{2 0 1 5}$ & $\mathbf{2 0 1 6}$ & TOTAL \\
\hline No. trámites devoluciones & 77.316 & 67.627 & 59.453 & 52.717 & 59.964 & 78.664 & 85.432 & 481.173 \\
\hline $\begin{array}{l}\text { Programas abiertos } \\
\text { DEVOLUCIONES }\end{array}$ & 13.950 & 11.749 & 10.011 & 8.673 & 8.710 & 8.170 & 8.782 & 70.045 \\
\hline $\begin{array}{l}\text { Índice de trámites de devolu- } \\
\text { ción investigados en progra- } \\
\text { ma de fiscalización }\end{array}$ & $\mathbf{1 8 , 0 4} \%$ & $\mathbf{1 7 , 3 7 \%}$ & $\mathbf{1 6 , 8 4 \%}$ & $\mathbf{1 6 , 4 5 \%}$ & $\mathbf{1 4 , 5 3 \%}$ & $\mathbf{1 0 , 3 9 \%}$ & $\mathbf{1 0 , 2 8 \%}$ & $\mathbf{1 4 , 5 6 \%}$ \\
\hline
\end{tabular}

Fuente: Coordinación de Devoluciones y Compensaciones - Subdirección de Gestión de Recaudo y Cobranzas. 
Del cuadro anterior, se observa que dentro de los años 2010-2016 se realizaron 481.173 solicitudes de compensación y/o devolución (DIAN, 2017), de las cuales 70.045 fueron evaluadas en el proceso de fiscalización tributaria, lo que representa que el 14,56 \% de las solicitudes elevadas a la DIAN, además de pasar por los controles establecidos en el proceso de Recaudación, tuvieron evaluación así fuera de carácter formal en las áreas de Fiscalización mediante el programa Devolución Impuestos “DI”, en el que se efectúa un análisis preliminar dentro del proceso de fiscalización tributaria.

No obstante, en cuanto al adelantamiento de programas de fondo abiertos en la gestión de fiscalización tributaria en los años 2010-2015 ${ }^{11}$, solo se adelantaron un total de 11.469, por lo que casi tres (3) de cada cien (100) solicitudes de compensación y/o devolución, tuvieron un control tributario de fondo de parte del proceso de fiscalización, de la forma así expuesta (véase cuadro 12).
En consecuencia de lo anterior, si bien es verdaderamente importante realizar controles intensivos, de fondo y más exhaustivos a las solicitudes de compensación y/o devolución de impuestos para que se otorguen en atención a la ley y a la realidad económica de los contribuyentes, es importante que estos mecanismos se ubiquen dentro de las actividades del proceso de recaudación, por lo que es necesario analizar los controles de la gestión de las devoluciones y/o compensaciones, redefiniendo los que sean necesarios para que dentro de las solicitudes electrónicas se adelanten cruces de información que comprueben automáticamente la realidad de las retenciones y/o saldos a favor, y así garantizar que estas solicitudes se otorguen a quienes cumplen las condiciones legales, procurando así no desgastar la gestión de la fiscalización tributaria, toda vez que para tener un alcance mediano al control de fondo de la gestión de las devoluciones y/o compensaciones, si se acude a la capacidad operativa de la fiscalización tributaria, la misma se vería

\section{Cuadro 12. Trámites compensaciones y/o devoluciones solicitadas frente a programas de fiscalización de fondo abiertos por devoluciones}

\begin{tabular}{|l|c|c|c|c|c|c|c|}
\hline \multicolumn{1}{|c|}{ No. solicitudes/año } & $\mathbf{2 0 1 0}$ & $\mathbf{2 0 1 1}$ & $\mathbf{2 0 1 2}$ & $\mathbf{2 0 1 3}$ & $\mathbf{2 0 1 4}$ & $\mathbf{2 0 1 5}$ & TOTAL \\
\hline No. trámites devoluciones & 77.316 & 67.627 & 59.453 & 52.717 & 59.964 & 78.664 & 395.741 \\
\hline $\begin{array}{l}\text { No. programas fiscalización de } \\
\text { fondo por DEVOLUCIONES }\end{array}$ & 2.988 & 2.709 & 1.782 & 1.373 & 1.265 & 1.352 & 11.469 \\
\hline $\begin{array}{l}\text { Índice de trámites de devolución } \\
\text { investigados en programa de } \\
\text { fiscalización }\end{array}$ & $\mathbf{3 , 8 6 \%}$ & $\mathbf{4 , 0 1 \%}$ & $\mathbf{3 , 0 0 \%}$ & $\mathbf{2 , 6 0 \%}$ & $\mathbf{2 , 1 1} \%$ & $\mathbf{1 , 7 2} \%$ & $\mathbf{2 , 9 0} \%$ \\
\hline
\end{tabular}

Fuente: Coordinación de Devoluciones y Compensaciones - Subdirección de Gestión de Recaudo y Cobranzas.

\footnotetext{
${ }^{11}$ No se cuenta con información disponible del año 2016 respecto a número de investigaciones de fondo por Devoluciones y/o Compensaciones.
} 
agotada y casi que anulada ${ }^{12}$ por desviarse en una alta medida de los aspectos esenciales para los que fue creada, que se relacionan con el cumplimiento de las obligaciones tributarias, la reducción de la evasión y el fomento al cumplimiento voluntario de las obligaciones.

\section{B. Investigaciones de fiscalización} relacionadas con declaraciones tributarias adelantadas en los años 2010-2016, frente al número de declaraciones presentadas en los años 2009-2014.

De un análisis del número de las investigaciones de fiscalización abiertas relacionadas con declaraciones tributarias, se observa una disminución en su cantidad, que desde el año 2010 al año 2016 se ha visto reducida en más de una cuarta parte (véase gráfico 3 )

En consecuencia, dicho número de investigaciones abiertas en 2010-2016 se redujo drásticamente en un $67,40 \%$, lo que refleja una política de control tributario tendiente a reducir el control intensivo en lo referente a la revisión de declaraciones tributarias.

Por otra parte, el número de declaraciones presentadas en 2009-2016 ha presentado variaciones constantes. Sin embargo, se ha puesto dentro de un rango de 9,4 millones a 13,9 millones, volumen que frente al número de investigaciones de fiscalización abiertas relacionadas con declaraciones, refleja un alcance muy reducido del control intensivo.

A continuación, se presenta un comparativo de las declaraciones tributarias presentadas en los años 2009-2015 frente al número de investigaciones relacionadas con declaraciones tributarias adelantadas dentro del año inmediatamente siguiente a la presentación de la declaración, en el que eventualmente se adelantarían las labores de control de las declaraciones tributarias presentadas en el año anterior (véase cuadro 12).

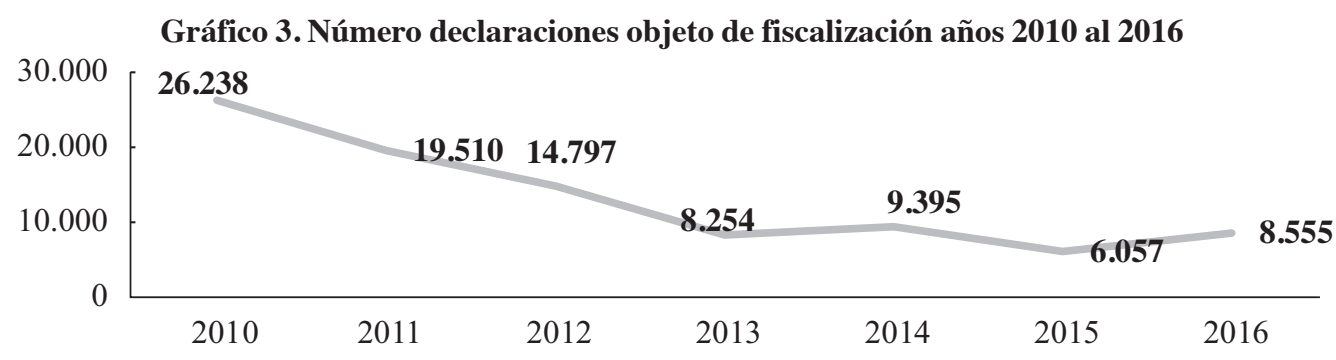

Fuente: Coordinación de Gestión Operativa de la Subdirección de Gestión de Fiscalización Tributaria.

\footnotetext{
${ }^{12}$ Como se observa de las cifras expuestas en los cuadros, de 2010 a 2016 se presentaron 481.173 solicitudes de compensación y/o devolución, frente a la capacidad operativa de los programas de fiscalización, que asciende a 283.375 en el mismo periodo.
} 
Cuadro 13. Declaraciones presentadas en los años 2009-2015 frente al número de programas de fiscalización abiertos relacionados con declaraciones en los años 2010-2015

\begin{tabular}{|l|c|c|c|c|c|c|c|c|}
\hline $\begin{array}{l}\text { 1. Total declara- } \\
\text { ciones presenta- } \\
\text { das 2009 a 2014 }\end{array}$ & $\mathbf{2 0 0 9}$ & $\mathbf{2 0 1 0}$ & $\mathbf{2 0 1 1}$ & $\mathbf{2 0 1 2}$ & $\mathbf{2 0 1 3}$ & $\mathbf{2 0 1 4}$ & $\mathbf{2 0 1 5}$ & Total \\
\cline { 2 - 9 } & 13.943 .055 & 12.695 .528 & 12.411 .070 & 9.434 .897 & 9.529 .191 & 10.291 .583 & 10.517 .998 & 78.823 .322 \\
\hline $\begin{array}{l}\text { 2. Número progra- } \\
\text { mas fiscalización } \\
\text { relacionados con } \\
\text { declaraciones }\end{array}$ & $\mathbf{2 0 1 0}$ & $\mathbf{2 0 1 1}$ & $\mathbf{2 0 1 2}$ & $\mathbf{2 0 1 3}$ & $\mathbf{2 0 1 4}$ & $\mathbf{2 0 1 5}$ & $\mathbf{2 0 1 6}$ & Total \\
\cline { 2 - 9 } & 26.238 & 19.510 & 14.797 & 8.254 & 9.395 & 6.057 & 8.555 & 92.806 \\
\hline $\begin{array}{l}\text { Índice de decla- } \\
\text { raciones tributa- } \\
\text { rias presentadas } \\
\text { que son objeto } \\
\text { de fiscalización } \\
\text { (2./ 1.) }\end{array}$ & $\mathbf{0 , 1 9 \%}$ & $\mathbf{0 , 1 5 \%}$ & $\mathbf{0 , 1 2} \%$ & $\mathbf{0 , 0 9 \%}$ & $\mathbf{0 , 1 0 \%}$ & $\mathbf{0 , 0 6 \%}$ & $\mathbf{0 , 0 8 \%}$ & $\mathbf{0 , 1 2} \%$ \\
\hline
\end{tabular}

Fuente: Coordinación de Gestión Operativa de la Subdirección de Gestión de Fiscalización Tributaria y Coordinación de Control a Entidades Recaudadoras de la Subdirección de Gestión de Recaudo y Cobranzas.

Teniendo en cuenta las cifras anteriores, se encuentra que dentro de los años 20102015, aproximadamente una de cada mil (1.000) declaraciones tributarias fue objeto de apertura de una investigación de fiscalización, pero la tendencia subsecuente de los años analizados va encaminada a reducir el número de investigaciones tributarias frente a un incremento en el número de declaraciones presentadas, donde esta situación no se ha dado por una priorización o focalización de las acciones en determinados sectores de la economía, prácticas negociales, actividades económicas o en los contribuyentes que presenten mayores valores de evasión que se identifiquen a partir de un perfilamiento de riesgos de evasión tributaria que permita concentrar y direccionar los esfuerzos donde más se desarrollan estas prácticas de evasión.

En consecuencia, resulta contradictoria esta disminución en el número de investigaciones y acciones individualizadas (que no obedece a una priorización en la gestión aprovechando la capacidad operativa del control tributario) frente al incremento en el número de declaraciones tributarias presentadas, lo que puede tener un impacto negativo en la percepción de riesgo subjetivo, ya que al reducirse el alcance del control tributario intensivo por declaración, podría reflejar en los obligados tributarios una apreciación de inacción e inactividad del impulso del control tributario, donde si bien se restringen las actividades en este sentido, no se evidencia que se efectúe con el propósito de mejorar los resultados, la eficiencia o la focalización de la fiscalización.

Así las cosas, si mediante iniciativa gubernamental se pretende que las reformas tributarias contemplen la creación de nuevos impuestos incrementando así la base de declaraciones tributarias y de igual forma se busca incluir nuevas figuras de control tributario que impliquen mayores exigencias a los contribuyentes, las modificaciones deberían considerar la realidad del escenario institucional y operativo del ente fiscal que ejerce el control tributario, con el fin de que las reformas también contemplen la adecuación de la realidad institucional a la configuración 
normativa y regulatoria tributaria, con el propósito de consolidar un sistema tributario eficaz y no simplemente que se adopten figuras jurídicas y controles tributarios en normas inertes, sin aparato estatal que las haga realidad, por lo que se encuentran acertadas las afirmaciones de la Comisión de expertos para la equidad y la competitividad tributaria (2015), que en el Capítulo V de su informe final precisa que para enfrentar los grandes retos tributarios, el país requiere con urgencia de una reorganización profunda de varios de los aspectos operativos y legales de la actual administración.

\section{Investigaciones de fiscalización relacionadas con declaraciones tributarias frente al universo de contribuyentes}

Para analizar el impacto que tiene la tendencia en la disminución del número de in- vestigaciones de fiscalización adelantadas por la DIAN dentro de los años 2010-2016 frente al universo de contribuyentes, en el siguiente aparte se hace una comparación de los programas abiertos relacionados con declaraciones frente al número de obligados en los años 2010 a 2016, a presentar declaración de renta e inscritos en el régimen común con responsabilidad frente al impuesto a las ventas.

\section{Investigaciones de fiscalización frente al número de obligados en el impuesto de renta}

Realizando una comparación entre el número de obligados a presentar declaración de renta en los años 2010-2016 frente al número de investigaciones abiertas relacionadas con declaraciones dentro de los mismos años, se observa el siguiente comportamiento:

\section{Cuadro 14. Número de obligados renta frente a investigaciones fiscalización relacionadas con declaraciones}

\begin{tabular}{|l|c|c|c|c|c|c|c|c|}
\hline Concepto/año & $\mathbf{2 0 1 0}$ & $\mathbf{2 0 1 1}$ & $\mathbf{2 0 1 2}$ & $\mathbf{2 0 1 3}$ & $\mathbf{2 0 1 4}$ & $\mathbf{2 0 1 5}$ & $\mathbf{2 0 1 6}$ & $\begin{array}{c}\text { Promedio } \\
\mathbf{a n ̃ o s} \mathbf{2 0 1 0} \text { a } \\
\mathbf{2 0 1 6}\end{array}$ \\
\hline $\begin{array}{l}\text { Número obl. } \\
\text { Renta }\end{array}$ & 1.941 .446 & 2.054 .590 & 2.177 .863 & 2.331 .167 & 3.418 .867 & 3.873 .834 & 4.160 .026 & 3.326 .299 \\
\hline $\begin{array}{l}\text { Número } \\
\text { investigaciones } \\
\text { fiscalización } \\
\text { relacionadas } \\
\text { con } \\
\text { declaraciones }\end{array}$ & 26.238 & 19.510 & 14.797 & 8.254 & 9.395 & 6.057 & 8.555 & 15.468 \\
\hline $\begin{array}{l}\text { Estimación } \\
\text { declaraciones } \\
\text { fiscalizadas } \\
\text { por año }\end{array}$ & $\mathbf{1 , 3 5 \%}$ & $\mathbf{0 , 9 5 \%}$ & $\mathbf{0 , 6 8 \%}$ & $\mathbf{0 , 3 5 \%}$ & $\mathbf{0 , 2 7} \%$ & $\mathbf{0 , 1 6 \%}$ & $\mathbf{0 , 2 1} \%$ & $\mathbf{0 , 4 7} \%$ \\
\hline
\end{tabular}

Fuente: Coordinación de Gestión Operativa de la Subdirección de Gestión de Fiscalización Tributaria y Subdirección de Gestión de Asistencia al Cliente. 
Observando este incremento en el número de obligados a presentar declaración de renta, teniendo en cuenta que dentro de los años 2010-2016 se pasó de 1.941.446 a 4.160.026, que representa un aumento en el universo de un $114,27 \%$, llama la atención que en la misma proporción de crecimiento de este número no crezca la capacidad operativa de fiscalización, así como los programas de fiscalización diseñados y el número de investigaciones abiertas.

Contrariamente, se está contrayendo drásticamente el control intensivo, sin tener en cuenta la importancia de estas acciones en el impacto de la percepción del riesgo subjetivo y las altas brechas de evasión en este impuesto, que como se señaló, se ubican en unas tasas de $39 \%$ para el año 2014 en personas jurídicas, y la evasión en personas naturales, tasas comparativamente más altas frente a las de las personas jurídicas en este impuesto (BID, 2013), por lo que llama la atención la política tributaria de la DIAN tendiente a la contracción del control intensivo de cara a modificaciones normativas tributarias que incrementan este universo de obligados en relación con dicho impuesto.

Así el propósito de la Administración Tributaria tal vez se enmarque en focalizar la fiscalización reduciendo las acciones y estableciendo ciertas prioridades para cumplir sus metas, de otro lado, la legislación tributaria que surge con iniciativa del Gobierno Nacional ha promovido el incremento en el número de declarantes cuando se están reduciendo las acciones y la capacidad institucional de control, lo que desvirtúa la constitución de un sistema tributario eficiente, ya que si es la voluntad de la administración reducir y focalizar el control, no debe imponer a la ciudadanía el cumplimiento de obligaciones tributarias que se apartan de su alcance.

Más bien, si a su consideración resulta prudente focalizar el control tributario, entonces sería conveniente reducir el universo de los obligados de cara a la eficiencia del sistema tributario y de no imponer mayores cargas públicas a los agentes económicos que no va a controlar, máxime si se tiene en cuenta que en la reforma tributaria de la Ley 1819 del 29 de diciembre de 2016 se establecieron varias figuras e instituciones de control como el Régimen de Entidades Controladas del Exterior (Artículo 882 del Estatuto Tributario), el establecimiento de controles específicos a las Entidades del Régimen Tributario Especial (Artículos 140 a 164 de la Ley 1819 de 2016), los controles sobre el monotributo (Artículos 165 y siguientes de la Ley 1819 de 2016), los controles frente al cumplimiento de las obligaciones de suministro de información por parte de los beneficiarios efectivos (Artículos 132 a 134 de la Ley 1819 de 2016), nuevos obligados frente a las disposiciones del Régimen de Precios de Transferencia, entre otros.

Las cargas administrativas y de fiscalización generadas a partir de la creación de estas nuevas figuras de control tributario que desprenden funciones adicionales a la Administración, vendrían a sopesar aún más la baja capacidad de control institucional de la DIAN, lo que se vería afectado si no se fortalece el aparato institucional vigente, ya que los escasos esfuerzos, recursos y capacidades con las que se cuenta en la actualidad, que han sido insuficientes y escasamente técnicos y calificados para cumplir las funciones de control tributario, se verían menguados por una redistribución de dichos esfuerzos a partir del establecimiento de estas nuevas 
responsabilidades de control, cuando con las ya establecidas en la actualidad, los recursos son insuficientes.

2. Investigaciones de fiscalización frente al número de inscritos en el régimen común

El mismo comportamiento anterior se observa respecto al incremento en el número de responsables del régimen común, cuya tendencia en 2010-2016 frente a la disminución en el número de investigaciones tuvo el siguiente comportamiento (véase cuadro 15).

En consecuencia, como ya se ha advertido, la DIAN reduce su cobertura y capacidad operativa y las normas crean más obligaciones, figuras de control tributario, impuestos (impuesto al consumo, monotributo, entre otros) e incrementan el universo de declarantes y de obligados, lo que deriva en más declaraciones presentadas, mayor número de responsabilidades y más obligaciones a controlar, creándose así una tendencia al incremento en el número de declaraciones y obligaciones, inversamente proporcional a la capacidad de realizar control tributario sobre los deberes y sujetos de fiscalización.

En este orden de ideas, frente al número de inscritos en el régimen común en los años
2010-2016, se observa un incremento al pasar de 727.506 en el año 2010 a 1.190 .868 en 2016, lo que representa un incremento de un $63,69 \%$, donde, concomitantemente para el mismo periodo, el control tributario no intensifica ni amplía su cobertura, como se vio en apartes anteriores y, por lo contrario, la reduce inversamente al incremento en sujetos obligados objeto de control, donde se denota una política de control tendiente a reducir los alcances de la fiscalización sin tener en cuenta las altas brechas de evasión tributaria expuestas en apartes anteriores del presente trabajo, por lo que llama la atención que la política de control tributario de la DIAN tienda a la contracción en el control intensivo, frente a un incremento en el número de inscritos en el régimen común dentro de los periodos analizados, que además deriva mayores responsabilidades frente al establecimiento de otros impuestos, como el impuesto al consumo.

\section{La gestión efectiva de fiscalización frente al control de legalidad y el recaudo de actos oficiales}

En desarrollo del presente trabajo, dentro de la revisión de los instrumentos de medición y evaluación de la gestión del control tributario, se encontró que los planes ope-

Cuadro 15. Número de inscritos en régimen común frente a investigaciones de fiscalización relacionadas con declaraciones

\begin{tabular}{|l|c|c|c|c|c|c|c|}
\hline \multicolumn{1}{|c|}{ Concepto/año } & $\mathbf{2 0 1 0}$ & $\mathbf{2 0 1 1}$ & $\mathbf{2 0 1 2}$ & $\mathbf{2 0 1 3}$ & $\mathbf{2 0 1 4}$ & $\mathbf{2 0 1 5}$ & $\mathbf{2 0 1 6}$ \\
\hline Régimen común & 727.506 & 789.208 & 853.028 & 926.308 & 1.002 .388 & 1.073 .661 & 1.190 .868 \\
\hline $\begin{array}{l}\text { Número inv. Fiscalización rela- } \\
\text { cionados con declaraciones }\end{array}$ & 26.238 & 19.510 & 14.797 & 8.254 & 9.395 & 6.057 & 8.555 \\
\hline $\begin{array}{l}\text { Estimación declaraciones fis- } \\
\text { calizadas por año }\end{array}$ & $\mathbf{3 , 6 1 ~ \%}$ & $\mathbf{2 , 4 7} \%$ & $\mathbf{1 , 7 3} \%$ & $\mathbf{0 , 8 9} \%$ & $\mathbf{0 , 9 4} \%$ & $\mathbf{0 , 5 6} \%$ & $\mathbf{0 , 7 2} \%$ \\
\hline
\end{tabular}

Fuente: Coordinación de Gestión Operativa de la Subdirección de Gestión de Fiscalización Tributaria y Subdirección de Gestión de Asistencia al Cliente. 
rativos fijan dos tipos de metas, a saber: i) metas de gestión, que están referidas a evacuación de expedientes y cargas de trabajo, y ii) metas de resultados, siendo esta última la relativa a la "gestión efectiva de fiscalización" propiamente dicha, que se relaciona con los valores de actos oficiales ejecutoriados y no ejecutoriados, producidos por fiscalización y liquidación tributaria, a la cual se hizo referencia en apartes anteriores.

No obstante, tanto de la verificación de todos los instrumentos de medición y evaluación existentes como de las indagaciones realizadas para efectuar este trabajo, no se encontró un instrumento que hiciera converger la mera producción de actos con su efectividad en el recaudo (en fiscalización y liquidación o en sede administrativa en discusión con correcciones provocadas, o en el proceso de administración de cartera), o una evaluación o medición en términos de que los resultados de la gestión efectiva de fiscalización superaran un filtro de legalidad, aspecto que materializaría el modelo de gestión por procesos de la DIAN ${ }^{13}$, donde se podría evaluar y controlar la gestión institucional considerada en una forma integrada y consolidada.

\section{Conclusiones}

1. El instrumento que mide los resultados operativos del control tributario en la DIAN lo constituye la "meta de gestión efectiva de fiscalización", pero no se han diseñado elementos de evaluación que mi- dan los resultados de la fiscalización frente al comportamiento de la evasión, a fin de determinar la incidencia que el desempeño y presión del control tributario ejercen sobre esta. El instrumento que por excelencia mide los resultados del control tributario lo constituye la "meta de gestión efectiva de fiscalización" que comprende valores de actos oficiales ejecutoriados y no ejecutoriados producidos en desarrollo de procedimientos tributarios individualmente considerados.

No obstante, se considera insuficiente que los resultados de este proceso se midan a partir de una simple producción de actos, y llama la atención que hasta la fecha y para todos los años analizados y anteriores a estos, no se hayan diseñado otros elementos de evaluación que midan los resultados de la gestión del proceso de control tributario frente al comportamiento de la evasión, con el fin de hacer medible la efectividad del desempeño de la fiscalización de cara al cumplimiento voluntario de las obligaciones tributarias, donde se considera que la fiscalización tributaria, más que buscar el cumplimiento de una meta dineraria de producción de actos oficiales, debe propender principalmente a disminuir la evasión fiscal.

\section{La priorización del control extensivo y perceptivo reduciendo el control intensivo,} si bien ha conseguido cumplir las metas establecidas, no ha contribuido a reducir las brechas de evasión. El número de investigaciones de fiscalización adelantadas de 2010 a 2016 ha presentado un drástico recorte, 
pasando de abrir 68.207 en 2010 a 30.110 en 2016 , con un decremento del $55,85 \%$ en el periodo analizado, lo que es dado por la intensificación y mayor alcance de las acciones de control tributario extensivo y perceptivo y a los resultados logrados en materia de sobrecumplimientos en metas de gestión efectiva.

No obstante, si se tiene en cuenta que a pesar de que con dicha priorización del control extensivo se ha conseguido cumplir holgadamente las metas de gestión efectiva de fiscalización, los resultados de las mediciones muestran que la evasión no se ha visto reducida, por lo que resulta llamativo tal nivel de contracción del control intensivo cuando el país presenta unos comportamientos de evasión tributaria altos comparativamente frente a países OCDE (OCDE, 2015), los cuales no han bajado la guardia sino que, como se vio, tienden a incrementarse en tasas y valores absolutos y, además, como se advirtió, hay cálculos de evasión extraoficiales que demuestran que el escenario parcial de evasión tributaria presentado por la DIAN puede llegar a ser más gravoso.

En consecuencia, este hecho no debería conllevar a reducir a tal magnitud el control intensivo, el cual consiguientemente debería incrementarse, teniendo en cuenta adicionalmente el incremento en número de declarantes en los años 2010 a 2016, que en renta aumentó el universo en un 114,27 \%, y en inscritos en el Régimen Común en un 63,69\%, así como las últimas reformas tributarias crearon más impuestos y figuras jurídicas de control tributario, circunstancias que reflejan la necesidad de que dicho tipo de acciones debería incrementarse.
3. Relación inversa entre el incremento en el número de sujetos obligados tributarios, la creación en las reformas tributarias de nuevos impuestos y figuras jurídicas de control, frente a una reducción de acciones de control tributario intensivo, la baja capacidad operativa institucional y el escaso aprovechamiento a la oportunidad de fortalecimiento dado en la Ley 223 de 1995 - Plan de choque contra la evasión. Conforme al comportamiento en el número de investigaciones de fiscalización, la baja capacidad operativa institucional y el escaso aprovechamiento a la oportunidad de fortalecimiento dado en la Ley 223 de 1995 - Plan de choque contra la evasión en el periodo 2010-2016, se observa que la Administración Tributaria ha contraído el control tributario intensivo frente a un incremento en el número de declarantes, declaraciones, inscritos en el Régimen Común para el mismo periodo, sin observarse que se mejore técnicamente y se fortalezca la capacidad institucional de control, lo que desvirtúa la constitución de un sistema tributario eficiente, toda vez que si es la voluntad de la administración reducir y focalizar el control, no debe imponer a la ciudadanía el cumplimiento de obligaciones tributarias que se apartan del alcance de su control.

Lo anterior, máxime si se tiene en cuenta que en la reforma tributaria de la Ley 1819 del 29 de diciembre de 2016 se establecieron varias figuras e instituciones de control como el Régimen de Entidades Controladas del Exterior (Artículo 882 del Estatuto Tributario), el establecimiento de controles específicos a las Entidades del Régimen Tributario Especial (Artículos 140 a 164 de la Ley 1819 de 2016), los controles sobre el monotributo (Artículos 165 y siguientes de la Ley 1819 de 
2016), los controles frente al cumplimiento de las obligaciones de suministro de información por parte de los beneficiarios efectivos (Artículos 132 a 134 de la Ley 1819 de 2016), nuevos sujetos obligados a cumplir con las disposiciones del Régimen de Precios de Transferencia, entre otros, las cuales vendrían a recargar aún más la baja capacidad de control institucional de la DIAN, lo que se vería afectado si no se fortalece el aparato institucional vigente, ya que los escasos esfuerzos, recursos y capacidades con los que se cuenta en la actualidad se verían menguados por una redistribución de dichos esfuerzos a partir del establecimiento de nuevas responsabilidades de control cuando con las ya establecidas en la actualidad los recursos son insuficientes, y donde no se utilizó de la mejor forma la oportunidad de fortalecimiento del control tributario dado mediante las previsiones de la Ley 223 de 1995 - Plan de choque contra la evasión, y estaría por verse si se fortalece el recurso humano con base en las nuevas disposiciones de la Parte "XIV Administración tributaria" de la Ley 1819 del 29 de diciembre de 2016.

\section{Sobrecumplimientos excesivos de las} metas de gestión efectiva de fiscalización dentro del periodo 2011-2016 se podrían dar por la fijación de metas sin tener en cuenta los altos comportamientos de evasión fiscal, lo que genera una subestimación del alcance real del control tributario y del potencial operativo del control tributario institucional y/o falta de consistencia en el instrumento de evaluación por basarse en la simple producción de actos. La gestión efectiva de fiscalización (valores de actos oficiales producidos en fiscalización y liquidación) en el periodo de enero de 2011 a diciembre de 2016 ha sobrecumplido sus metas en un 159,20\%, toda vez que en dicho periodo se han proferido actos oficiales que respaldan sumas por $\$ 22,95$ billones cuando la meta se ha fijado en $\$ 14,41$ billones, lo que podría indicar, desde un punto de vista general y muy preliminarmente, una gestión exitosa.

No obstante, dicha situación se podría dar porque en la fijación de los valores de las metas no se tiene en cuenta el comportamiento de la evasión fiscal, generándose una subestimación del alcance real que debe tener el control tributario, así como de la productividad y el potencial operativo de la fiscalización tributaria institucional, y/o por falta de consistencia en el instrumento de medición y evaluación por basarse en la simple producción de actos.

Llama la atención que la Administración no haya replanteado la forma de medir los resultados de la gestión de este proceso y, contrariamente, este indicador se mantiene en la actualidad (2017) y se ha utilizado desde vigencias anteriores a las analizadas y se ha constituido como el elemento único y por excelencia para evaluar los resultados de la gestión de fiscalización, situación que podría generar una cultura administrativa de que dichos comportamientos son normales y hasta sinónimo de una gestión exitosa que supera las expectativas, sin que se hayan sopesado dichos resultados de cara a las altas tasas de evasión fiscal que se han mantenido a lo largo de los periodos analizados.

\section{La medición del recaudo de los va-} lores de los actos oficiales, así como su control de legalidad, permitiría evaluar la materialización de la gestión de fiscalización y la efectividad del régimen 
sancionatorio tributario, a fin de tomar medidas que generen un impacto real en la percepción del riesgo subjetivo y el fomento al cumplimiento voluntario de las obligaciones. La DIAN no evalúa los resultados del control de legalidad de los actos oficiales, así como su recaudo, lo que le permitiría evaluar la materialización de la gestión de fiscalización, la efectividad del régimen sancionatorio tributario y la gestión consolidada e integral de todos los procesos tributarios de la Administración, ya que lo que se pierde con la evasión tributaria son recursos públicos, y lo que consecuentemente se debería medir es la capacidad de recuperación de los mismos.

Si se parte de la premisa de que un aspecto es la producción de actos y otro son los resultados que devienen de su control de legalidad así como de su recaudo, se considera que la mera producción de actos sin filtro de legalidad y sin evaluar la recuperación de los recursos afecta de igual manera la percepción de riesgo subjetivo y el cumplimiento voluntario de las obligaciones, toda vez que se generaría una apreciación subjetiva en los contribuyentes de que los actos generados en el control tributario no tienen consecuencias económicas reales, donde el recaudo de los valores materializa y convierte en una realidad la gestión efectiva de fiscalización, siendo necesario evaluar la efectividad del régimen sancionatorio tributario, teniendo en cuenta que dichos papeles superen un filtro de legalidad y sean convertibles en recursos donde efectivamente se contrarreste la evasión, dirigiendo las acciones de fiscalización contra quienes incurren en sus prácticas, las cuales van a tener consecuencias económicas reales y materializables que trascienden la expedición de un acto oficial por la recuperación de los dineros públicos.

\section{El comportamiento en los valores de} recaudo tributario frente a los porcentajes del PIB de los años 2014 a 2016, permitirían señalar que las tasas de evasión estimadas en renta del año 2013 se han mantenido para los años 2014 a 2016. A pesar de no contar con cifras actualizadas de medición de la evasión en renta para los años 2014 a 2016, la evasión en este impuesto para estos años puede presentar una tendencia mayor a la observada en el último año analizado, que correspondió a 2013, ya que los valores de recaudo en renta (sumando el impuesto de renta para la equidad CREE) para el año 2013, así como los de los años 2014 a 2016, no presentan el mismo dinamismo del crecimiento del Producto Interno Bruto (PIB) de estas mismas vigencias, donde los incrementos del PIB generaron mayores ingresos para la economía en general y para los diversos agentes económicos, pero no produjeron un mayor recaudo impositivo, por lo que las estimaciones oficiales de evasión que para renta personas jurídicas del año 2013 la ubicaban en $35,6 \%$, permitirían inferir que para los años 2014 a 2016 reflejarían unas tasas de evasión superiores.

\section{La planeación DIAN 2014-2018 se en-} foca en la necesidad de modernización del control tributario, pero no se desprende este propósito mediante iniciativas, acciones, actividades, recursos y responsables que materialicen su ejecución y lo hagan realizable. En los instrumentos de la planeación DIAN se incluyen objetivos tácticos para fortalecer la fiscalización, que se refieren al diseño de programas innovadores de control 
basados en las operaciones internacionales, los precios de transferencia, identificación de nuevos nichos evasores u omisos, acciones integrales TACI, entre otros (GM3), pero de estos:

i) no se desprenden iniciativas, acciones o actividades que materialicen su consecución, donde el éxito de los instrumentos de planeación radica en la determinación concreta de las acciones, responsables, tiempos, recursos, y elementos de seguimiento y medición;

ii) se ha reducido el número de funcionarios en las diferentes áreas involucradas en estas actividades, como la Subdirección de Gestión de Fiscalización Internacional y la Coordinación de Programas de Control y Facilitación, que consecuentemente reducen su capacidad operativa;

iii) las nuevas disposiciones del Régimen de Precios de Transferencia contempladas en la Ley 1819 del 29 de diciembre de 2016 amplían la base de sujetos obligados a cumplir obligaciones de este régimen, incrementándose así el alcance del control en estos aspectos sin que se destinen correlativamente recursos para controlar estas nuevas actividades; $y$

iv) persiste una ausencia de expertos en estos temas técnicos, lo que dificulta llevar a una realidad el propósito de modernizar el control tributario.

En el objetivo táctico relacionado con la suscripción de acuerdos de cooperación e intercambio de información con incidencia tributaria y aduanera (GM6), las iniciativas, acciones específicas, responsables, recursos y tiempos solo hacen referencia a los acuerdos en temas aduaneros y de comercio exterior, sin incluir acciones frente a los acuerdos de información con relevancia tributaria, siendo de trascendental importancia dichos intercambios de información con fines tributarios para el control a los impuestos corporativos cuando los sujetos obligados realizan operaciones internacionales, donde la OCDE aboga por el intercambio de información entre las autoridades fiscales para contrarrestar la evasión tributaria (OCDE, 2009).

Respecto al objetivo táctico referente a profundizar en el conocimiento de los contribuyentes mediante técnicas de inteligencia de negocios y gestión de riesgos (GM8), la DIAN no dispone de un sistema de gestión de riesgos medianamente estructurado y funcional para estos fines, existiendo un déficit de personal técnico para desarrollar estas funciones, sin que desde el punto de vista de perfilamiento del riesgo tributario se ejerza actividad o control alguno, lo que dificulta la implementación de un sistema de control tributario basado en la gestión de riesgos con perfilamiento de contribuyentes, siendo una imperante necesidad que se focalice el control tributario en determinados sectores de la economía, prácticas negociales sofisticadas, actividades económicas o en los contribuyentes que presenten mayores valores de evasión, que se identificarían a partir de un perfilamiento de riesgos que permita direccionar los esfuerzos donde más se desarrollan estas figuras evasivas.

\section{Desgaste del control tributario con} ocasión de la gestión de devoluciones y/o compensaciones. De la gestión por programas de fiscalización del año 2010 al 2016 
(7 años), la cuarta parte de la fuerza de la fiscalización tributaria se destinó a coadyuvar labores de Recaudación en la Gestión de las Compensaciones y Devoluciones, donde si bien es importante realizar controles intensivos, de fondo y más exhaustivos a estos trámites, estos mecanismos se deben adelantar dentro del proceso de recaudación y excepcionalmente en la fiscalización, por lo que los controles de las solicitudes electrónicas deben comprender análisis de fondo mediante cruces de información que comprueben automáticamente la realidad de las retenciones y/o saldos a favor, procurando así no desgastar la gestión de la fiscalización tributaria, que se debe focalizar en la reducción de la evasión tributaria.

\section{Los recursos presupuestales de inver- sión del plan de choque contra la evasión} no han sido destinados en su totalidad al control de la evasión. Los recursos del "Proyecto Implantación Plan de choque contra la evasión" en su gran mayoría se destinan a la vinculación de personal de carácter temporal, el cual no se encuentra vinculado en su totalidad para realizar labores de control tributario y aduanero, como lo consagra la Ley $223 \mathrm{de}$ 1995, ya que de los 1.853 funcionarios financiados con recursos de este plan, solo el $29 \%$ realiza funciones de fiscalización, sin tener en cuenta que estos recursos tienen una destinación específica y representan una prioridad dentro de la política gubernamental para el fortalecimiento del control fiscal a la evasión.

\section{Referencias}

Auditoría y Planeación Tributaria (2015, octubre). Recuperado de http://documents.mx/documents/auditoriayplaneaciontributariapdf.html.

Banco Interamericano de Desarrollo (BID) (2013). "More than Revenue: Taxation as a Development Tool", en A. Corbacho, V. Fretes y E. Lora (editores), Development in the Americas, Inter-American Development Bank, Palgrave McMillan, Nueva York, (2013).

Banco Mundial (BM) (2013). Doing Business 2014: Understanding Regulations for Small and Medium-Size Enterprises. Grupo del Banco Mundial, Washington, DC. (2014).

Banco Mundial (BM) (2015). “Colombia: Declaración Final de la Misión de Consulta del Artículo IV de 2015”, Misión de Consulta del Artículo IV de 2015, Washington, DC. Recuperado de http://www.imf.org/es/ news/articles/2015/09/28/04/52/mcs032415.

Banco Mundial (BM) (2017). Tasa de incidencia de la pobreza, sobre la base de la línea de pobreza nacional (\% de la población)", Grupo del Banco Mundial, Washington, DC. Recuperado de http://datos.bancomundial. org/indicador/SI.POV.NAHC.

Camargo, D. (2005), Evasión fiscal: un problema a resolver. Eumed.net (abril 2016). Recuperado de http:// www.eumed.net/libros-gratis/2005/dfch-eva/.

Centro Interamericano de Administraciones Tributarias - CIAT - Dirección de Estudios e Investigaciones Tributarias (2015). Estimación del Esfuerzo Tributario en los países de América Latina y el Caribe, Rossignolo, D. y Pecho, M., Panamá. Octubre de 2015.

Colombia. Ministerio de Hacienda y Crédito Público Dirección General de Apoyo Fiscal (2007). Manual de Fiscalización de Entidades Territoriales. Bogotá, D.C.

Comisión de Expertos para la Equidad y la Competitividad Tributaria (2015). Informe final presentado al Ministro de Hacienda y Crédito Público. Diciembre de 2015, Bogotá, D.C. Colombia.

Comisión Económica para América Latina y el Caribe (Cepal) (2016). Tributación para un crecimiento inclusivo. Ruiz, S.; Cañete, R.; Hanni, M.; Martner. R. y Titelman, D. Santiago de Chile. Marzo de 2016. Recuperado de http://repositorio.cepal.org/bitstream/ handle/11362/39949/S1600238_es.pdf;jsessionid=38 C428F8BA59ADE67AF20254F4C3D8EE? sequence $=1$.

Comisión Económica para América Latina y el Caribe (Cepal) (2015). Desigualdad, concentración del ingreso y tributación sobre las altas rentas en América Latina. Jiménez, J., Santiago de Chile. Abril de 2015. Recuperado de http://repositorio.cepal.org/bitstream/ handle/11362/37881/S1420855_es.pdf?sequence=1.

Comisión Económica para América Latina y el Caribe (Cepal) (2015). Consideraciones sobre el índice de GINI para medir la concentración del ingreso. Recu- 
perado de http://www.cepal.org/deype/mecovi/docs/ TALLER6/20.pdf.

Cruz, A. (2015). Tarifas efectivas promedio de las personas jurídicas - Año 2013. Bogotá, D.C.

Diccionario Jurídico (2017, junio). Recuperado de https://www.diccionariojuridico.mx.

Hubner, G. (1993). "Métodos utilizados para la selección de contribuyentes a auditar", en Revista Trimestre Fiscal No. 42 (1993). Guadalajara, JAL. Indetec, México (1993).

Organización para la Cooperación y el Desarrollo Económicos (OCDE) (2009). Next steps for OECD Global Forum on information exchange for tax purposes. Trabajo de la OCDE sobre evasión fiscal. Recuperado de https:// www.oecd.org/ctp/exchange-of-tax-information/ nextstepsforoecdglobalforumoninformationexchangefortaxpurposes.htm.

Organización para la Cooperación y el Desarrollo Económicos (OCDE) (2012). Informalidad y política fiscal en América Latina. II Foro LAC Política Tributaria.

Organización para la Cooperación y el Desarrollo Económicos (OCDE) (2015), Estudios económicos de la OCDE Colombia. (enero 2015). Recuperado de https://www.oecd.org/eco/surveys/Overview_Colombia_ESP.pdf.

Piza, J. (2011). "La función de fiscalización tributaria en Colombia", en Revista de Derecho Fiscal No. 7. Universidad Externado de Colombia: Bogotá, Colombia (2011). Recuperado de http://revistas.uexternado. edu.co/index.php/fiscal/article/view/3934/4227.

Soto, C. y Concha, A. (2011), “¿Reglas Fiscales en Colombia?", en Revista Fasecolda No. 28 (2011). Recuperado de https://www.fundacionmapfre.org/documentacion/publico/i18n/catalogo_imagenes/grupo. cmd?path=1060806.

Steiner, R. y J.C. Medellín (2014), "Parte II: Elementos para una nueva reforma tributaria", en Perspectiva Fiscal 2014-2018. Fedesarrollo, (abril 2014). Recuperado de http://www.repository.fedesarrollo.org.co/ handle/11445/1684.

Torres, D.; Jiménez, H.; Quiñones, E. (2012). La moralidad tributaria y riesgo de evasión tributaria. Caso de estudio con las sociedades del Ecuador registradas en el Servicio de Rentas Internas (SRI) (2012). Tesis de Grado. Guayaquil - Ecuador. Facultad de
Economía y Negocios. Escuela Superior Politécnica del Litoral (ESPOL). Recuperado de https://www. dspace.espol.edu.ec/bitstream/123456789/24630/1/ La\%20moralidad\%20tributaria\%20y\%20riesgo\%20 de $\% 20$ evasi $\%$ C3\%B3n $\% 20$ tributaria.Caso $\% 20 \mathrm{~d} \% 20$ estudio $\% 20$ con $\% 201$ a $\% 20$ sociedad $\% 20$ del $\% 20$ Ecuador.pdf.

\section{Normatividad}

Colombia, Ministerio de Hacienda y Crédito Público. Decreto 4048 (22 de octubre de 2008), "Por el cual se modifica la estructura de la Unidad Administrativa Especial Dirección de Impuestos y Aduanas Nacionales”. Bogotá, D.C.

Congreso de la República de Colombia. Ley 223 (22 de diciembre de 1995), "Por la cual se expiden normas sobre racionalización tributaria y se dictan otras disposiciones”. Diario Oficial 42160. Bogotá, D.C. Diciembre 22 de 1995.

Congreso de la República de Colombia. Ley 872 (30 de diciembre de 2003), "Por la cual se crea el sistema de gestión de la calidad en la Rama Ejecutiva del Poder Público y en otras entidades prestadoras de servicios". Diario Oficial No. 45.418. Bogotá. Enero 02 de 2004.

Congreso de la República de Colombia. Ley 1473 (5 de julio de 2011), "Por medio de la cual se establece una regla fiscal y se dictan otras disposiciones". Diario Oficial No. 48.121. Bogotá. 5 de julio de 2011.

Congreso de la República de Colombia. Ley 1607 (26 de diciembre de 2012). "Por la cual se expiden normas en materia tributaria y se dictan otras disposiciones". Diario Oficial 48655. Bogotá, D.C. Diciembre 26 de 2012.

Congreso de la República de Colombia. Ley 1819. (29 de diciembre de 2016). "Por medio de la cual se adopta una reforma tributaria estructural, se fortalecen los mecanismos para la lucha contra la evasión y la elusión fiscal, y se dictan otras disposiciones". Diario Oficial 1819. Bogotá, D.C. Diciembre 29 de 2016.

Instituto Colombiano de Normas Técnicas y Certificación (ICONTEC). "Norma Técnica de Calidad en la Gestión Pública NTCGP 1000:2009”, Bogotá, D.C.

Colombia. Dirección de Impuestos y Aduanas Nacionales - DIAN. Resolución 134 (22 de diciembre de 2015), "Por medio de la cual se crea la Coordinación Integral de Lucha contra el Contrabando y la Evasión Fiscal”, Bogotá, D.C. 
Colombia. Dirección de Impuestos y Aduanas Nacionales - DIAN. Resolución 2546 (19 de marzo de 2010), "Por la cual se modifica y adiciona la Resolución 0011 del 4 de noviembre de 2008”. Bogotá, D.C.

Colombia. Dirección de Impuestos y Aduanas Nacionales - DIAN. Resolución 4105 (22 de abril de 2009), "Por la cual se modifica y adiciona la Resolución 0011 del 4 de noviembre de 2008, modificada por la Resolución 00782 del 27 de noviembre de 2008 y por la Resolución 02281 del 30 de diciembre de 2008”. Bogotá, D.C.

Colombia. Dirección de Impuestos y Aduanas Nacionales - DIAN. Resolución No. 010 (4 de noviembre de 2008), "Por la cual se autoriza el funcionamiento de las Direcciones Seccionales Delegadas de Impuestos y Aduanas de la Unidad Administrativa Especial Dirección de Impuestos y Aduanas Nacionales". Bogotá, D.C.

Dirección de Impuestos y Aduanas Nacionales - DIAN. Resolución No. 11 (4 de noviembre de 2008), "Por la cual se crean Grupos Internos de Trabajo y se asignan funciones en la Unidad Administrativa Especial Dirección de Impuestos y Aduanas Nacionales". Bogotá, D.C.

\section{Documentos de la Dirección de Impuestos yAduanas Nacionales}

Dirección de Impuestos y Aduanas Nacionales - DIAN. "Análisis de los principales indicadores fiscales y económicos mundiales que inciden sobre el comportamiento de Colombia. Versión 1. Octubre de 2014". (2014). Bogotá, D.C.

Dirección de Impuestos y Aduanas Nacionales - DIAN. Cadena de valor procesos DIAN - Mapa de procesos. (2017). Bogotá, D.C.

Dirección de Impuestos y Aduanas Nacionales - DIAN.Cifras Planeación DIAN 2009 al 2016. (2017). Bogotá, D.C.

Dirección de Impuestos y Aduanas Nacionales - DIAN. Código de Buen Gobierno, DIAN. (2017) Bogotá, D.C.

Dirección de Impuestos y Aduanas Nacionales - DIAN. Comunicado de Prensa DIAN No. 56 de abril de 2016. (2016) Bogotá, D.C.

Dirección de Impuestos y Aduanas Nacionales - DIAN. "Documento Entorno para la Gestión 2016 y recomen- daciones para la Inversión DIAN" de la Subdirección de Gestión de Análisis Operacional - Coordinación de Planeación y Evaluación. Diciembre de 2015. (2016). Bogotá, D.C.

Dirección de Impuestos y Aduanas Nacionales - DIAN. Estadísticas declaraciones - Coordinación de Control a Entidades Recaudadoras de la Subdirección de Gestión de Recaudo y Cobranzas DIAN. (2017). Bogotá, D.C.

Dirección de Impuestos y Aduanas Nacionales - DIAN. Estadísticas Ingresos tributarios 1970-2017, RUT, inscritos Régimen Común, Obligados Renta - Subdirección de Gestión Asistencia al Cliente DIAN. (27, junio, 2017). Bogotá, D.C.

Dirección de Impuestos y Aduanas Nacionales - DIAN. Estadísticas solicitudes de devoluciones y/o compensaciones - Coordinación de Devoluciones y Compensaciones de la Subdirección de Gestión de Recaudo y Cobranzas DIAN. (2017). Bogotá, D.C.

Dirección de Impuestos y Aduanas Nacionales - DIAN. Información Contratación, planes de compras y planes anuales de Adquisiciones DIAN 2012 al 2016. (2016). Bogotá, D.C.

Dirección de Impuestos y Aduanas Nacionales - DIAN. Información presupuestal DIAN 2011 al 2016. (2017). Bogotá, D.C.

Dirección de Impuestos y Aduanas Nacionales - DIAN. Informes de Gestión y Resultados de la Dirección de Gestión de Fiscalización y de la Subdirección de Gestión de Fiscalización Tributaria. (2017). Bogotá, D.C.

Dirección de Impuestos y Aduanas Nacionales - DIAN. Informes Plan de Choque contra la Evasión DIAN, años 2010 al 2016. (2017). Bogotá, D.C.

Dirección de Impuestos y Aduanas Nacionales - DIAN. Manual de Funciones. (2017). Bogotá, D.C.

Dirección de Impuestos y Aduanas Nacionales - DIAN. Manual lineamientos fiscalización DIAN. (2013). Bogotá, D.C.

Dirección de Impuestos y Aduanas Nacionales - DIAN. Orden Administrativa 003 de 2010 de la Dirección de Gestión de Fiscalización de la DIAN. (2010). Bogotá,D.C.

Dirección de Impuestos y Aduanas Nacionales - DIAN. Orden Administrativa 11 del 5 de octubre de 2009 de 
la Dirección de Gestión de Fiscalización de la DIAN. (2009). Bogotá, D.C.

Dirección de Impuestos y Aduanas Nacionales - DIAN. Plan Estratégico, Plan Táctico e Iniciativas Tácticas DIAN 2014-2018. (2017). Bogotá, D.C.

Dirección de Impuestos y Aduanas Nacionales - DIAN. Planes operativos de Fiscalización DIAN, años 2010 al 2016. (2017). Bogotá, D.C.

Dirección de Impuestos y Aduanas Nacionales - DIAN. Planta DIAN - Coordinación de Nómina de la Subdirección de Gestión de Personal. (2016). Bogotá, D.C.
Dirección de Impuestos y Aduanas Nacionales - DIAN. Procedimientos del subproceso de Control Tributario del Proceso de Fiscalización y Liquidación: PR-FL-0220, PR-FL-0221 y PR-FL-0222. (2017). Bogotá, D.C.

Dirección de Impuestos y Aduanas Nacionales - DIAN. Proceso de Fiscalización y Liquidación CP-FL-0009 y Subproceso de Control Tributario. (2017). Bogotá,D.C. 